\title{
Does the Tail Wag the Dog? \\ The Price Impact of CDS Trading*
}

\author{
Dragon Yongjun Tang ${ }^{\dagger}$ \\ The University of Hong Kong \\ Hong Yan $^{\ddagger}$ \\ University of South Carolina \\ and Shanghai Advanced Institute of Finance
}

This version: November 2010

\begin{abstract}
We investigate empirically whether credit default swaps (CDS) spreads are influenced by shifts in demand/supply dynamics in the market. We find that while changes in CDS spreads are insensitive to accumulated trading volume, net buying interest (NBI), a measure we construct to measure latent trade imbalance between consecutive trades, significantly affects CDS price changes. This price impact appears to be statistically significant even in the absence of concomitant stock price changes, but its economic magnitude is on par with the average bid-ask spread. While changes in fundamental information contribute to the price impact of net buying interest, liquidity of CDS contracts is another factor. We show that the effect of NBI is three times stronger in the least liquid CDS contracts than in the most liquid CDS contracts. Furthermore, exogenous supply shocks attenuate the initial price impact and accelerate the subsequent price reversal.
\end{abstract}

${ }^{*}$ We thank Sudipto Dasgupta, Stephen Figlewski, Ming Guo, Jean Helwege, Xuewen Liu, Laura Liu, Mark Seasholes, Tan Wang, and John Wei for discussions, and seminar participants at the Hong Kong University of Science and Technology and the Shanghai Advanced Institute of Finance for useful comments. This research is supported by a Q-Group grant. Ying Deng has provided excellent research assistance.

${ }^{\dagger}$ School of Economics and Finance, University of Hong Kong, Pokfulam Road, Hong Kong. Tel.: (852) 22194321. Email: yjtang@hku.hk

${ }^{\ddagger}$ Current Address: Shanghai Advanced Institute of Finance, 211 West Huai Hai Road, Datong Plaza, Shanghai, China 200030. Tel.: (86) 21-62932031. Email: yanh@moore.sc.edu 


\title{
Does the Tail Wag the Dog? The Price Impact of CDS Trading
}

\begin{abstract}
We investigate empirically whether credit default swaps (CDS) spreads are influenced by shifts in demand/supply dynamics in the market. We find that while changes in CDS spreads are insensitive to accumulated trading volume, net buying interest (NBI), a measure we construct to measure latent trade imbalance between consecutive trades, significantly affects CDS price changes. This price impact appears to be statistically significant even in the absence of concomitant stock price changes, but its economic magnitude is on par with the average bid-ask spread. While changes in fundamental information contribute to the price impact of net buying interest, liquidity of CDS contracts is another factor. We show that the effect of NBI is three times stronger in the least liquid CDS contracts than in the most liquid CDS contracts. Furthermore, exogenous supply shocks attenuate the initial price impact and accelerate the subsequent price reversal.
\end{abstract}

JEL Classification: G12; G13; E43; E44

Keywords: credit default swaps; latent trading imbalance; liquidity 


\section{Introduction}

The US credit crisis in 2007 and 2008 and the European sovereign crisis in 2010 have focused much attention on the trading in the credit default swaps (CDS) market. CDS contracts are insurance-like credit derivatives with payoffs contingent on a default or restructuring event of the reference issues. After the explosive growth of the CDS market in the decade before the credit crisis, many are now concerned that trading in credit default swaps could cause, rather than insure against, the default of reference issuers. As CDS trading figured prominently in the default of Lehman Brothers and the collapse of AIG in 2008 and in the Greek debt crisis in 2010, there have been calls for tougher regulations and even an outright ban on certain types of CDS transactions. ${ }^{1}$ Yet there is thus far little, if any, empirical evidence establishing the link between CDS trading and CDS spreads (see, e.g., Stulz (2010)). In this paper, we investigate empirically whether and how trading activity in CDS contracts may affect CDS spreads.

In a complete and frictionless market, derivative securities are redundant and their trading activity should not affect their prices and those of the underlying securities. However, in the presence of information asymmetry or market frictions, trading in derivatives can potentially impact the pricing of these securities. For instance, guarding against adverse selection, CDS sellers would demand higher prices in buyer-initiated transactions, and buyers would likewise offer lower prices when approached by sellers. Even in absence of information asymmetry, CDS prices may be affected by funding constraints such as those articulated in Brunnermeier and Pedersen (2009). Bollen and Whaley (2004) and Garleanu, Pedersen, and Poteshman (2009) illustrate the implications of these considerations for the price pressure effect in the options market. CDS contracts, however, are not traded on exchanges as most options, and the lack of transparency and regulation has been argued as a key weakness that could make the CDS market prone to insider trading and manipulation. ${ }^{2}$ Thus, both from an academic standpoint and a regulatory perspective, it is important to understand better the impact of trading activities on CDS prices.

In order to identify supply/demand shifts and their potential pricing effects, aggregated

\footnotetext{
${ }^{1}$ For instance, in summer 2009, influential investor George Soros proposed to ban CDS contracts altogether. In March 2010, the Prime Minister of Greece blamed the CDS market for his country's soaring CDS spreads and borrowing costs, and solicited an international coalition to curb CDS trading. In May 2010, Germany banned naked CDS buying which is regarded as creating "excessive price movements" and endangering financial stability.

${ }^{2}$ Acharya and Johnson (2007) present evidence for insider trading in the CDS market. ...
} 
low-frequency data are less powerful since private information and liquidity shocks are usually short lived. In our study, we use a CDS transactions dataset from GFI Group, a leading interdealer broker for CDS trading, that contains trades and quotes on corporate names in North America between January 2002 and April 2009. This allows us to construct a unique measure of latent trade imbalance for a particular contract, which we call "net buying interest" (NBI), and investigate its impact on CDS prices.

As illustrated in previous studies of price pressure effects, ${ }^{3}$ the association of fundamental information and demand shocks clouds the assessment of the price pressure effect across different securities markets. We find that levels of CDS spreads are positively associated with numbers of quotes and trades, as demand for credit protection should be negatively related to an underlying name's credit quality, and hence positively associated with its credit spread. However, changes in CDS spreads are generally insensitive to numbers of quotes and trades at the weekly frequency. Similar patterns generally hold at the monthly frequency except for the case of extremely large numbers of trades in a month, which could be due to credit deterioration of an underlying name that ramps up the demand over the period of a month.

The accumulated number of trades and quotes over a fixed period of time masks the constant shift in the supply/demand shocks. Given the zero net supply of CDS contracts, the imbalance of trades may play an important role in moving market prices. Indeed, there are concerns that surges in demand for specific CDS contracts, coordinated or not, may have contributed to the financial crisis in 2008 and the Greek crisis in 2010. To examine this issue more closely, we construct for each contract a variable of NBI, defined as the difference in the number of bids and the number of offers between two consecutive trades. In a market equilibrium, NBI should be zero on average if dealers have sufficient confidence and funding to make the market. However, NBI may become large in magnitude when liquidity provisions are insufficient or market uncertainty becomes large.

Our analysis reveals a strong positive relation between changes in CDS spreads and the net buying interest. All else equal, one additional bid (buy interest) is associated with a $1.5 \%$ increase in the CDS price on average (or an increase of 3.7 basis points on average).

\footnotetext{
${ }^{3}$ For primary securities markets, an early study of Kraus and Stoll (1972) and many others since demonstrate that dynamics of supply and demand shocks can move stock prices. Chordia, Roll, and Subramanyam (2002), Chordia and Subramanyam (2004), Coval and Stafford (2007), Sarkar and Schwartz (2009), and Hendershott and Menkveld (2010) study effects of order imbalance and price pressure in stock markets. Greenwood and Vayanos (2010) and Krishnamurthy and Vissing-Jorgensen (2010) illustrate the effects of demand/supply imbalance for government bonds. Ellul, Lundblad, and Jotikasthira (2009) and Ambrose, Cai, and Helwege (2010) discuss price pressure effects for corporate bonds.
} 
The group with the largest NBI experiences a $16 \%$ price increase while the group with the most negative NBI (largest net selling interest) experiences a 10\% price decrease. Even for consecutive transactions taking place within a day, namely, more liquid names, the difference in the price impact between these two groups is still significant at $5 \%$ (3.9\% vs. $-1.1 \%$ ).

In order to control for changes in the fundamentals of underlying names, we separate contracts according to their concurrent stock prices changes. It appears that the price impact of demand shifts as measure by NBI persists among contracts with little concomitant changes in stock prices. The evidence shows that among these contracts, those in the large positive NBI group see on average a 3.8\% increase in CDS prices and those in the large negative NBI group have on average a $3.6 \%$ price decrease. This effect remains robust statistically after controlling for firm and market factors that may affect net buying interest and CDS change simultaneously. However, the economic magnitude of this effect may be in question as it is on par with the average bid-ask spread.

In addition, the effect of the net buying interest is found to be associated with both market liquidity and funding liquidity, consistent with the theoretical argument in Brunnermeier and Pedersen (2009). The effect is the strongest when the bid-ask spread is wide and when the demand shock is large. It is also stronger for lower-rated reference issuers as their CDS spreads are more likely to be volatile and dealers may find it costly to maintain open positions. We demonstrate that the price impact due to the net buying interest was particularly pronounced after the collapse of Bear Stearns in March 2008 and again in September 2008 when Lehman Brothers failed. This evidence may lend support to the prediction of Allen and Carletti (2006) who show that price impact may exacerbate the contagion induced by credit risk transfer.

Moreover, we find that net buying interest has predictive information for future changes in CDS spreads, as following a large net CDS buying interest, CDS spreads continue to rise another $10 \%$ in addition to the initial $16 \%$ price increase. However, this predictive ability appears to be associated with significant stock price changes. In fact, positive demand shocks seem to be endogenous to the changes in credit quality as the trades with large NBIs and large concomitant stock price changes usually settle at higher CDS spreads after five trades. In contrast, net selling interest appears to have little information content as the price impact of negative NBIs is reversed quickly.

An exogenous supply shock in the CDS market occurs when synthetic collateralized debt obligations (CDOs) are issued. Synthetic CDOs sell CDS contracts to synthesize the cash flows of reference bonds. We find that when the synthetic CDO issuance activity is high, the 
price impact of large net CDS buying interest is significantly smaller, even after controlling for the general market funding level usually measured by the TED spread (i.e., U.S. Treasuries over Eurodollar spread). This implies that when funding constraints are not binding and market liquidity is at an adequate level, non-information-based shocks in demand (or supply) may have little price impact.

Despite the importance of the CDS market in the recent financial crisis and an increasing number of studies of CDS contracts since the early studies of Longstaff, Mithal, and Neis (2005) and Blanco, Brennan, and Marsh (2005), there is still a dearth of systematic analysis of trading in the market (Stulz, 2010). ${ }^{4}$ This study fills this gap by employing transaction-level data to provide evidence on the pricing effect of demand for liquidity in the CDS market.

While quantifying liquidity effects is important for improving credit risk modeling and hedging strategies, our work also sheds light on the subject of intense regulatory discussions. Because banning naked CDS buying will effectively reduce the net CDS buying interest due to limited supply of reference bonds, our analysis implies that such action may not be necessary because the informationless price impact identified in our study is short lived as long as there is adequate supply of liquidity. A ban may actually hamper information production in the market and reduce market liquidity and efficiency. Even though it appears that large net buying interests are associated with large increases in CDS spreads, our analysis further shows that fundamentals are still the driving force as only issuers of deteriorating credit risk are susceptible to a significant price pressure effect.

The rest of this paper is organized as follows: Section II provides some background information on the CDS market and our dataset. Section III documents the relationship between CDS trading, in particular, net buying interest, and the change in CDS spreads. We analyze aspects of this relationship in Section IV. Section V concludes.

\footnotetext{
${ }^{4}$ There are several recent papers discussing liquidity effects in the CDS markets, including Bongaerts, De Jong, Driessen (2010), Bühler and Trapp (2009), and Tang and Yan (2008).
} 


\section{The CDS Market and Data Description}

\section{A The CDS Market}

The invention of credit default swaps is commonly attributed to J.P. Morgan which in 1994 contracted with the European Bank of Reconstruction and Development (EBRD) on a $\$ 4.8$ billion credit line to Exxon. J.P. Morgan would pay a periodic fee to EBRD until the contract expires or Exxon defaults. In the latter event EBRD would cover J.P. Morgan's loss. ${ }^{5}$ In this case, J.P. Morgan is the buyer of CDS protection, and EBRD is the protection seller. Exxon is the reference entity, and the reference issue is the credit line. The notional amount of the contract is $\$ 4.8$ billion.

The standardization of CDS contracts was stipulated by the 1999 ISDA Master Agreement. Both the size and the diversity of the CDS market had increased dramatically until the credit crisis in 2007. In addition to single-name CDS and basket products, index and CDS derivatives started trading in 2004. According to the ISDA survey, the total notional amount of outstanding CDS contracts peaked at $\$ 62$ trillion by the end of 2007 , but it dropped to $\$ 30$ trillion by the end of $2009 .^{6}$

Until recently, the CDS market had been largely unregulated and CDS transactions were conducted mostly over-the-counter. Market participants are almost entirely institutions, including many financial conglomerates. There is little transparency in market size and counterparty risk. ${ }^{7}$ In the aftermath of the financial crisis of 2007-2008, new rules and regulations are being introduced to improve the functioning of the CDS market in both the U.S. and Europe. These new rules, however, are in place after the end of our data series, so they will not affect the analysis in this paper.

Most CDS contracts are traded through dealers. Dealers either trade with other dealers directly or trade through an interdealer broker. Flow traders fill orders for their clients. Proprietary trading desks buy and sell CDS contracts for profits like hedge funds. For the market-making purpose, a flow trader may warehouse certain positions of outstanding CDS

\footnotetext{
${ }^{5}$ For more details, see Tett (2006).

${ }^{6}$ The BIS estimate shows the total 2009 year-end notional amount as $\$ 32.7$ trillion and market value of $\$ 1.8$ trillion ( $\$ 21.9$ trillion and $\$ 1.2$ trillion, respectively, for single-name CDS contracts only). DTCC reports outstanding amount $\$ 14.6$ trillion for single-name contracts and $\$ 25$ trillion for all credit products as of May 7, 2010. OCC statistics for U.S. insured commercial banks by year-end 2009 is $\$ 14$ trillion.

${ }^{7}$ See Counterparty Risk Management Policy Group (CRMPG), headed by E. Gerald Corrigan, for more discussions. http://www.crmpolicygroup.org/
} 
contracts. Most dealers/traders use a hybrid trading system. A dealer may call a broker to place an order or execute a trade. She may also simply trade at an acceptable price displayed by an online quoting system such as MarketAxess, RealTime, or CreditMatch. Dealers can also enter their quotes into the system and wait for them to be hit. When anonymity is not essential, a trader may directly communicate with a counterparty to execute a trade.

\section{B Data Description}

Our dataset comes from GFI Group, which is a leading CDS market interdealer broker and has been ranked as a top credit broker by Risk magazine every year since 1998. The data are captured by GFI's CreditMatch electronic and voice hybrid trading system, which allows traders to enter, amend and remove their own quotes and prices and search historical databases. A trader's screen displays the order book which includes all tradable bid and offer prices and corresponding trade sizes for a reference name and the length of the contract. Relevant bond prices are also provided on the same screen. Unlike other data sources, the GFI dataset consists of only market prices, tradable quotes and transaction information.

Our data sample covers all intra-day quotes and trades on North American single names from GFI's trading platform between January 1, 2002 and April 30, 2009. Because of the over-the-counter market structure and the lack of a central clearing mechanism, there is not a single comprehensive data source for CDS transactions. To mitigate the concern about the representativeness of our data sample, we aggregate our firm-level data sample to obtain a market-level summary and then compare it with the market survey summary statistics from ISDA and OCC who collect data from their member dealers/banks. The ISDA survey is conducted semiannually with dealers all over the world. The OCC report is released quarterly containing information from American commercial banks regulated by OCC. Overall, trading activities recorded in our sample correlate well with those in the ISDA data with a correlation coefficient of 0.75 . As expected, our data sample matches better with the OCC reports with a correlation coefficient of 0.82 , as both focus on market participants in the US.

Our main analysis uses trades and quotes directly. In order to isolate the effects of contractual terms and term structure, we only use five-year CDS contracts on North American senior unsecured reference issues with modified restructuring in the settlement clause. To illustrate the type of data in our analysis, we plot in Figure 1 the quotes and traded prices for five-year CDS contracts on Yum! Brands in 2006. At the beginning of the year, a trade 
was executed at 60 basis points while the offer price was at about 75 basis points and the bid price at about 55 basis points. Then there were 13 bids and 15 offers before the next trade was executed at 45 basis points in April. Although the CDS spread had fallen 25\% during this period, the stock price had not changed much. Starting in August, stock prices started to rise substantially and the CDS spread kept dropping down to 23 basis points before it went back up to 42 basis points in December. During this late-year run-up, there were 8 bids and 4 offers.

Our final sample consists of 55,358 trades and 608,524 quotes from 861 corporate entities with appropriate financial and accounting data. We summarize our trade-level data in Table I. Panel A shows that trades in CDS contracts are highly clustered. While the average duration of time between two consecutive trades is 14.3 days the median is only about 50 minutes. There are on average about 11 quotes between consecutive trades with an average of 5.7 bids and 5.2 offers among these quotes. The average mid-quote is about 246 basis points, the average bid-ask spread is 14 basis points, or an average of $9.1 \%$ of the CDS mid-quote. On average, CDS spread increases by $2.1 \%$ between consecutive trades. Panel B documents the characteristics of reference issuers.

Figure 2 plots monthly time series of average CDS spreads and trading activities in our sample. Panel A shows that CDS spreads remain steady between 100 and 200 basis points until the downgrade of GM and Ford in May 2005, when CDS spreads reached about 400 basis points. CDS spreads declined afterwards until the summer of 2007, the onset of the credit crisis. Then they soared to around 1200 basis points in March 2009. On average, a reference issuer has about 2 trades per month. But the average trade volume increased to as much as 6 trades per month at the onset of the credit crisis in the summer of 2007. However, the average number of quotes has declined sharply since the downgrading of GM/Ford in May 2005. At the end of 2007, there were about 10 quotes per month for an average issuer.

\section{Trading Measures and CDS Spreads}

In this section, we document the effects of trading measures on CDS spreads. The trading measures we use include both volume-type measures accumulated over a fixed period of time and a measure of latent order imbalance that indicates a degree of supply-demand mismatch between trades. 


\section{A Volume-type Measures}

At both weekly and monthly frequencies, we count the number of trades or the total number number of trades and quotes for all contracts in our sample. The number of trades represents a measure of volume, and the total number of quotes and trades captures a measure of market interest. Then we average the CDS spreads for the contracts with the same number of trades or the same total number of trades and quotes. Figure 3 plots the logarithm of average CDS spreads against the total number of quotes and trades (top panel) or the total number of trades only (bottom panel) at both weekly frequency (left panel) and monthly frequency (right panel).

Generally, higher CDS spreads are associated with more trading activities. This observation implies that demand for credit protection is stronger on names with less pristine credit profiles. This positive relation is more prominent at the weekly frequency and when we measure trading activities by the total number of quotes and trades. At the monthly frequency, the relationship is weak especially for highly active contracts. This is consistent with the observation in the case of Yum! Brands and others that trades in CDS contracts appear to be clustered in time. Moreover, for most actively traded CDS contracts, i.e., those with at least 13 weekly trades or 27 monthly trades, the association between CDS spreads and trading activities becomes cloudy and mostly flat.

In order to delineate the price impact of CDS trading activities, we now link changes in CDS spreads to CDS trading activities. Again, for each number of trades or total number of trades and quotes, we obtain the averaged change in CDS spreads. Figure 4 plots the average change in CDS spreads against the total number of quotes and trades (top panel) or the number of trades only (bottom panel) at both the weekly frequency (left panel) and the monthly frequency (right panel). The graphs do not exhibit a clear pattern for the association between changes in CDS spreads and trading activities. This finding appears consistent with the notion that the dynamics of CDS spreads are not dependent upon trading activities in these contracts. A closer inspection, however, reveals one important observation: overall CDS spreads increase across the range of trade numbers as there are more positive changes than negative changes. The lower right panel also suggests that at the monthly frequency changes in CDS spreads are positively related to the total number of trades. This finding may indicate that intensive trading over an extended period of time can lead to large increases in CDS spreads. 
We further examine the impact of changes in accumulated trade measures on changes in CDS spreads. As shown in Figure 5, the patterns are rather puzzling. For contracts with little change in trading activities, they tend to experience large changes in CDS spreads, while for contracts that see large swings in trading activities, changes in CDS spreads tend to be small. In particular, we also see indications that the CDS market is essentially a demand-driven market, as for all positive changes in trade measures, average CDS spreads increase, while a drop in CDS trading activities can lead to a drop in CDS spreads. However, based on the evidence using the accumulated volume measures, there is little to suggest a price-pressure effect in the CDS market.

\section{B A Measure of Latent Trade Imbalance}

Accumulated volume measures may smooth out supply-demand shifts and fail to detect the impact of trade imbalances on price dynamics in the CDS market. Motivations to trade may determine whether trading causes prices to move. Sellers worry about dealing with informationally advantaged buyers and vice versa. Funding constraints faced by dealers may prevent them from meeting the surging demand. When the market is one-sided, prices need to adjust significantly to attract more participants to take the opposite side of the trade. Therefore, as indicated in the literature, trade imbalance may lead to the movement of market prices.

To capture the interest in trading in the CDS market, we take advantage of the availability of quote information in our dataset and define the net buying interest (NBI) in CDS contracts as:

$$
\text { NBI }=\text { Number of Bids }- \text { Number of Offers, }
$$

where we count the numbers of bids and offers between two consecutive trades. This measure is consistent with the notion of trade imbalance in Chordia and Subramanyam (2004). Since it is based on binding quotes, rather than actual trades, we regard it a measure of latent trade imbalance.

Figure 6 plots percentage changes of CDS spreads against the net buying interest. The percentage change in CDS spreads is averaged for each level of NBI and only those data points corresponding to averages obtained with more than ten observations are kept. The figure shows a strong positive relationship between CDS spread change and NBI. When NBI increases by one standard deviation, i.e., 2.8 more bids than offers, CDS spread increases by 
$6.2 \%$. This effect is large considering the sample average of CDS spread changes is $2.1 \%$.

Table II tabulates the results sorted on NBIs. Observations on CDS changes are placed in five groups: $N B I<-3,-3 \leq N B I<0,0<N B I \leq 3$, and $N B I>3$. The breaking point of $N B I=3$ is chosen because the sample standard deviation of NBI is 2.8. In the full sample, the group with the lowest NBIs (or biggest net selling interest) is associated with 9.6\% CDS spread decrease, and the group with highest NBIs is accompanied with $15.7 \%$ increase in CDS spreads. This relationship is monotonic across groups of different levels of NBIs.

To ensure that our results are not driven by outliers that may have long durations between trades, we examine the subsample of consecutive trades executed within twenty-four hours and find similar results: biggest net selling interest (lowest NBI) pushes CDS spreads down by $11.4 \%$, while biggest net buying interest (highest NBI) pushes CDS spreads up by $11.0 \%$. We also examine the subsample with BBB-rated names, which is the largest group of the corporate names in our sample, the finding is again similar, i.e., the biggest net selling interest group experiences a $9.4 \%$ drop in CDS spreads and the biggest net buying interest group sees a $14.1 \%$ spread increase.

The existence of this predictability in CDS spread changes could be due to limits to arbitrage, as in the absence of such limits, such predictability might be arbitraged away. To proxy for the limits to arbitrage, we use the bond-CDS spread differential, called basis. A wide basis may imply the existence of limits of arbitrage in the market, while a small bondCDS basis is indicative of efficient pricing. We construct the basis using bond transaction data extracted from TRACE. The last column of Table II shows the sorting results for the subsample with the absolute value of basis less than 100 basis points. The results indicate that the effect of net buying interest is still significant even among contracts with relatively efficient pricing. The largest net selling interest group is associated with a $5.6 \%$ price decrease, while the largest net buying interest is associated with a $16.5 \%$ price increase.

The empirical results above demonstrate a significant and robust relationship between the net buying interest and the change in CDS spreads. In the next section, we analyze the sources of this relationship and, specifically, investigate the roles of information and liquidity in explaining why and how net CDS buying interest affects CDS prices. 


\section{Analysis}

\section{A Information Content of Net Buying Interest}

From the perspective of information content, net buying interest can affect CDS price changes in three distinct but non-mutually-exclusive ways. First, net buying interest may be correlated with concurrent public information. When there is bad news about a reference issuer, more investors may want to buy CDS protection on the name immediately, and hence pushing up its CDS spread. Second, the CDS market may be slow in incorporating public information. For example, a piece of information may have been disseminated in and responded to by the stock market, but CDS traders may react to the information with a lag. Lastly, CDS net buying interest may be linked to informed trading. In such cases, even without public information, CDS sellers recognizing potential adverse selection will raise CDS prices when an unexpectedly large amount of buyer interest shows up. In this case, NBI can forecast future changes in CDS spreads.

\section{Concurrent Information}

To relate the price impact of NBI to concurrent public information, we double sort on NBI and stock price changes. Stock price changes are allocated into five buckets: big negative change $(<-2 \%)$ between two consecutive CDS trades, medium negative change $[-2 \%,-0.1 \%)$, negligible change $[-0.1 \%, 0.1 \%]$, medium positive change $(0.1 \%, 2 \%]$, and big positive change $(>2 \%)$. We then calculate the average CDS price change in this $5 \times 5$ matrix. Figure 7 plots those averages. It is clear that concurrent stock price changes are negatively related to CDS price changes. When stock price increases, firm leverage and volatility decrease, and hence the distance to default will drop. Therefore CDS spread should decrease. A careful inspection reveals that the relationship between stock return and CDS change is not perfectly monotonically negative, consistent with the findings in Kapadia and $\mathrm{Pu}(2010)$.

Our main concern is whether stock price changes drive the relationship between NBI and CDS price change. We make an inference by conditioning on stock price changes. Figure 7 reveals a monotonic relationship between net buying and CDS change for every stock return bucket. Even when stock price does not move much (the middle group for stock price change), highest net buying interest pushes CDS price up by $3.8 \%$ and highest net selling interest presses CDS price down by $3.6 \%$, according to the data tabulated in Panel A of Table III. 
The stock price change amplifies this positive relationship between net buying interest and CDS price change. The most significant price impact of net buying interest is for the group with stock price dropping by more than $2 \%$. In such a case, high net buying interest leads to $35.7 \%$ in the CDS price increase and high net selling interest is associated with a $3.2 \%$ price decrease, thus creating a wedge of $38.9 \%$.

The monotonicity in the effect of net buying interest suggests that this effect could be more important than the impact of stock price change on CDS spreads. This conjecture is verified in Panel A of Table III. When there is a big net CDS buying interest, CDS spread increases regardless how stock price has changed. In particular, even when stock price goes up by $2 \%$ or more, CDS spread increases by $3.0 \%$ if NBI is big. On the other hand, when net selling is big, CDS spread decreases regardless how stock prices have changed. Again even when stock price drops by $2 \%$ or more, when net selling is big, CDS spreads still decrease by $3.2 \%$. Those two extreme cases provide strong evidence that the effect of net buying interest exists independent of the effect of stock price change on the CDS spread change.

\section{Lagging Information}

Previous studies (e.g., Blanco, Brennan, and Marsh (2005)) argue that the stock market leads the CDS market in price discovery. If this is the case, delayed reactions to past information can lead to a latent trade imbalance in corresponding CDS contracts and CDS spread change simultaneously. To capture past information, we use the past five-day cumulative return. To separate the magnitude of the past information, we use $5 \%$ and $1 \%$, respectively, as cutoff points for significant change and moderate change in stock prices. We double sort on past five-day stock return and NBI, and then calculate the average CDS spread change in each of the $5 \times 5$ groups. The results are reported in Panel B of Table III.

The panel shows that the effect of net buying interest prevails in each of the past five-day stock price change groups. Even in the group when stock price experienced little change in the past five days, big net buying still pushes price up by $10.3 \%$ and big net selling pushes price down by $15.7 \%$. While we observe some influence of past stock returns on CDS changes, as for the big net selling group, CDS spreads increase by $1.0 \%$ when stock price drops by $5 \%$ or more in the past five days, the effect of net buying interest varies little across past return groups. This implies that the effect of NBI on CDS spreads is not driven by past stock market information. 


\section{Leading Information}

We have shown that even when stock prices do not change, the positive relation between net buying interest and CDS price change still exists. Therefore, past information and concurrent information cannot fully explain the net buying effect. Another information-related explanation is informed trading. If trading contains private information about fundamentals, the counter-party with rational expectation will adjust prices to account for adverse selection.

Private information will be reflected in prices in subsequent trading, when information is revealed publicly. Hence, current net buying interest should predict future CDS changes beyond the very next trade. In order to test the predictability of future CDS changes based on net buying interest, we track CDS price changes in the next five trades following big net buying interest or selling interest. Figure 8 reports cumulative returns following the current net buying interest. We further group the data by concurrent stock returns in order to pin down the location of private information. At trade 0, biggest net CDS buying interest - three or more buy quotes than sell quotes - coupled with stock price decreasing by $2 \%$ or more is associated with a 35\% CDS spread increase. Afterwards CDS spread continues to rise. Hence, for this group of large CDS buying into stock decline, the credit quality deteriorates, as signified by increasing CDS spreads, in the near future. The big net buying group with no stock price movement experiences a $6 \%$ CDS increase initially, but there is little change afterwards. Hence the NBI effect for this group seems not related to information. More interesting is the group with big net buying interest when stock price increases by $2 \%$ or more. The initial reaction is the smallest 3\%. However, in the next five trades, CDS spread continue to rise by $18 \% .^{8}$ One possible scenario for this pattern is that informed traders could time the market and use stock price movement to camouflage their informational trades.

Figure 8 also demonstrates that net CDS selling interest has little if any information at all. The group with big net selling interest coupled with no stock price change eventually has the price impact completely reversed in four trades. Even the group with stock price dropping by $2 \%$ or more has minimal total effect. If stock return has increased by more than $2 \%$, subsequent CDS spreads increase. Overall, CDS selling experiences subsequent price reversal.

Our finding suggests that CDS net buying interest has substantial information content but CDS net selling interest contains little fundamental information. This is consistent with anecdotal evidence that CDS sellers such as AIG are mostly uninformed.

\footnotetext{
${ }^{8}$ This finding is consistent to the spirit of Rally Before Crash pattern studied by Eberlein and Madan (2010).
} 


\section{Regression Analysis}

So far our findings on the effect of net buying interest and its interaction with information are based on univariate or bivariate sorts. Inferences obtained using these methods are susceptible to concerns of omitted variables. In order to further verify the robustness of above results, we regress CDS price changes on net buying interest as well as information content proxies, controlling for credit risk changes. Panel regression results are reported in Table IV.

We first verify that the relationship between net buying and CDS change carries through in continuous measures. One extra net buyer is associated with $1.9 \%$ increase in CDS prices, without controlling for information or credit risk change. The stand-alone $R^{2}$ by net buying is $3.2 \%$. This effect survives credit risk change and market condition controls, although the magnitude drops slightly to $1.5 \%$. When we add concurrent stock returns, the coefficient estimate for net CDS buying is not affected. We also confirm the negative relationship between stock price change and CDS change. The incremental $R^{2}$ is about $1.0 \%$ which is less than the stand-alone $R^{2}$ of net buying interest. Furthermore, controlling for past five-day stock price change does not affect the NBI effect.

Because both CDS spread change and surge in demand for credit protection can be caused by the deterioration in a firm's fundamentals, the relationship between CDS spread change and NBI is inherently endogenous. Even though we have controlled in regressions reported in Table IV changes in fundamentals, it may not be sufficient to resolve the issue of endogeneity, inducing a biased regression coefficient. Therefore, we carry out a two-stage simultaneous equation approach explicitly account for the endogenous relationship between CDS change and NBI and examine if the effect of NBI is still robust once the endogeneity is accounted for.

The result from this exercise presented in Table $\mathrm{V}$ shows that the effect of net buying interest is still significant. The regression coefficient is reduced a bit from 0.015 to 0.013 , and its t-statistic has dropped markedly from 27.65 to a more down-to-earth 3.94. The adjusted $R^{2}$, however, has increased from $29.5 \%$ to $35 \%$.

In addition, we also test the predictive power of net buying interest by regressing the CDS change over two consecutive trades on the net buying interest between the previous two consecutive trades. We add several indicators to pin down the specific place of information. The results are reported in Table VI. We find that net buying interest predicts future CDS changes. Moveover, the predictive power comes from buying rather than selling, especially with big net buying interest when stock price is also dropping. 
Such a predictive analysis can be affected by microstructure noise, as discussed by Asparouhovaa, Bessembindera, and Kalcheva (2010). Our goal is to explore whether net buying interest contains information about future credit risk change. We use Moody's KMV model to general Expected Default Frequency (EDF) which is not directly related to trading activities in the CDS market. On the right panel of Table VI we regress the change in EDF on lagged NBI and control variables for credit risk change. We find that indeed big net CDS buying with stock price dropping is the place most likely associated with information about future credit risk increase.

The results in Table VI suggest a stronger predictive power of net CDS buying for future CDS rather than future EDF changes. This difference between CDS and EDF could be related to the recovery rate. Even if CDS does not lead stocks, CDS trading could be informative as some events may affect stocks and CDS asymmetrically. This is due to recovery rate as another key determinant of CDS spread. Investors care about probability of default but much less so about recovery rate. Recovery rate change could even be independent of stock price changes. For example, when a firm borrows from the bank to buy back some corporate bonds, while firm leverage remains the same (hence stockholders are not affected), remaining bondholders may suffer significantly if bank loan is more senior than outstanding bonds. So change in debt structure may cause wealth transfer among debt-holders without affecting shareholder values.

\section{B The Role of Liquidity}

We have shown that CDS net buying interest has information content for future CDS price changes. This predictive power could be due to the fact that the CDS market may not be liquid enough (lack of market depth) to accommodate large orders such that informed traders may have to split their trades. On the other hand, the presence of informed trading mat deter the participation in the market by the uninformed traders and hence reduce the liquidity further. Moreover, funding constraints may also lead to trade imbalance and affect the impact of NBI on CDS price changes. In this subsection, we explore the role of liquidity in the NBI effect. 


\section{Duration of the Net Buying Effect}

We first examine how long the net buying effect lasts. After recording big net buying or selling interests, we trace the subsequent price changes and plot the average subsequent changes in Figure 9. It is shown that after five trades, one is no longer able to distinguish the initial big net buying or selling. The effect is much converged by the second trade. The wedge reduces from $26 \%$ to about $5 \%$ in the next trade. Although the groups with net buying interest continues to experience larger positive price changes, by the fifth trade both buying and selling group end up with $2 \%$ increase in CDS spread. Consistent with our previous finding that net buying rather than net selling interest carries information, big net selling group experience price reversal from the very next trade as the change becomes positive, while net buying group continues to have positive changes.

As we mentioned before, our analysis is based on a trade-level dataset, which offers several advantages. First, it does not require aggregation of data which may result in murkier measures. Second, Kyle and Obizhaeva (2010) argue that the fundamental elements of trading games are the same, only the pace of the game differs. Nevertheless, a horizon analysis is useful to separate out information from liquidity. Information effect is likely to be permanent but liquidity effect is temporary. We plot the weekly and monthly relationship between net buying and CDS change in Figure 10. It is shown that much of the net buying effect disappears at monthly frequency, especially when net buying is not big. Hence, it is important to retrieve price impact from trade-level data. Additionally, the change is most positive in the net buying region.

It is worth noting from Figure 10 that the extremely large net buying group appears different from others. At weekly frequency, big net buying on average results in big CDS price increase, but there is substantial heterogeneity. At monthly frequency, there is a strong positive relation between net buying and CDS price change. Those findings are consistent with our previous result that big net buying particularly carries more information. It is plausible that the more buyers show up to marketplace than sellers, the more likely there is private information.

\section{Market Liquidity}

Except for the group with extremely big net buying interest which is a relatively small portion of the sample, the price impact of NBI seems dissipating quickly with time and reversing for 
the net selling group. Such features are indicative of market liquidity effects. When market liquidity is high, trades are easier to be executed, cost of balancing buyers and sellers is low, price is less sensitive to trade size. Since we focus on trade data and the net buying interest between two consecutive trades, the quantity dimension ("depth") is fixed. So we will focus on the other two dimension of liquidity: matching efficiency and trading cost.

Dealers have two liquidity concerns when they act as market makers rather than trading for their own accounts. The first concern is the ease to balance its book. If it is difficult to unload a position to the market, the dealer may not want to take the position in the first place. The second concern is how costly it is to carry a position on its own book. If inventory cost is low then the dealer may be more inclined to taking on a position without worrying too much about being stuck with the position. Inventory costs include funding cost due to margin and collateral, as well as maintenance cost due to fluctuations in values. Liquidity is difficult to quantify. We use conventional liquidity measures in the literature.

We measure market liquidity by the bid-ask spread. The Bid-ask spread can be thought of as the return to dealers for making the market. When the bid-ask spread is narrow, the disagreement between buyer and seller is small. It is conceivable that a lower bid-ask spread facilitates trades better than a high bid-ask spread. If the net buying effect is related to market liquidity, we expect a bigger price impact from NBI with wider bid-ask spreads. Panel A of Figure 11 shows that it is indeed the case. We sort the data by its relative percentage bid-ask spread into five groups. In all five groups, CDS change increases with net buying. Table VII Panel A shows that in the smallest bid-ask spread group, the difference in CDS change between big net buying and big net selling is $13.7 \%$. In the largest bid-ask spread group, this difference increases to $42.2 \%$, which is about three times of the smallest bid-ask spread group. There is a perfect monotonicity in between.

It is also interesting to note that the relationship between CDS change and bid-ask spread is highly dependent on the level of net buying interest. For the big net selling group, change in CDS spread decreases with bid-ask spread. For the big net buying group, CDS spread change increases with bid-ask spread. Our finding provides strong evidence for a liquidity effect in the CDS market. Unlike stocks and bonds which have positive net supplies and hence positive liquidity premia, whether the buyer or seller needs liquidity in the CDS market is not always clear with zero-net supply in contracts. When sellers dominate the market and they need liquidity, buyers will be liquidity providers and capture liquidity premium by offering a lower price. On the other hand, when buyers dominate the market and sellers are hard to find, they 
pay a higher CDS price. Our result also reveals that in the CDS market it is hard to find an unconditional relation between CDS spread change and bid-ask spread, supporting the model prediction of Gehrig and Jackson (1998).

Another way to measure CDS market liquidity is demand for immediacy. When there is high trading interest as demonstrated by large number of quotes between two consecutive trades, demand for immediacy is high. Hence, we use the total number of quotes to measure liquidity demand. The results are reported in Panel B of Figure 11 and tabulated in Panel B of Table VII. Again, we find that the net buying effect is strongest when demand for immediacy is highest at $28.5 \%$ (for the group with more than fifteen quotes between consecutive trades). When demand for immediacy is low, the net buying effect is $9.5 \%$, about one-third of the effect for high demand group. Also the relationship between CDS spread change and demand for immediacy depends on the level of net buying interest. For the group of big net selling interest, CDS spread decreases with demand for immediacy. For the group of big net buying interest, CDS spread increases with demand for immediacy. This conditional relationship between demand for immediacy and CDS change corroborates our finding from the bid-ask spread. Therefore, it is important to identify the party with pricing power in the CDS market when we evaluate liquidity effect.

We use a multivariate regression to examine whether the liquidity effect identified in our bivariate analysis is robust and whether the liquidity effect is incremental to information consideration. We interact net buying with bid-ask spread to see if the net buying effect is stronger in biggest bid-ask spread group. Specification 1 in Table VIII confirms this conjecture. The group with largest bid-ask spread has bigger net buying effect. Its magnitude is also economically significant: above the median bid-ask spread group (bid-ask spread greater than $20 \%)$ the net buying effect is $19 \%$ larger (0.33\%/1.75\%). Additionally, the group with higher demand for immediacy also has stronger net buying effect. The above median group has twice stronger net buying effect than the below median group. Lastly, those interaction effects are robust to the control of information variables, credit risk changes, and market condition.

\section{Funding Liquidity}

Above results present pervasive evidence that market liquidity influences the magnitude of the price impact due to net buying interest. It remains to further understand the source of this liquidity effect. How much dealers are willing to make the market depends on its funding 
constraints. Brunnermeier and Pedersen (2009) show that market liquidity can be driven by funding liquidity. It is important to separate demand from supply to assess the effect of funding liquidity. The demand side is often driven by volatility. We find CCC and lower rated reference issuers display the strongest net buying effect. This result supports the notion of liquidity demand as firms near bankruptcy have volatile CDS spreads, resulting in higher inventory costs for dealers holding such CDS contracts. However, it is difficult to precisely measure liquidity demand at individual levels. Hence, we opt to test the funding liquidity constraint from the liquidity supply perspective.

It is difficult to identify the changes in supply of liquidity or funding liquidity for individual CDS contracts. However, we could measure market funding liquidity with more confidence. For example, during the credit crisis, there is a liquidity crunch and liquidity supply is sharply reduced. We plot the CDS changes from big net buying and selling over time in Figure 12. It is clear that the net buying effect is much bigger in the crisis period. The peak occured in October 2008 after Lehman bankruptcy and AIG bailout. It is worth noting that during the crisis, it is rare to observe instances of net CDS selling interest, and even for those instances with net CDS selling interest, CDS spread still increases.

A direct measure of funding supply in the CDS market is the issuance of synthetic collateralized debt obligations (CDOs). Synthetic CDOs sell CDS protections to synthesize cash flows of bonds. Hence synthetic CDO issuance can be a major source for CDS funding liquidity. We construct a monthly time series of synthetic CDO issuance pooling data from SDC Platinum, Securities Industry and Financial Markets Association (SIFMA), and all three major credit rating agencies as well as industry publication Asset-Backed Alert.

We regress CDS spread change in reaction to net buying interest on logarithm of synthetic CDO issuance. Results are reported in Panel A of Table IX. We analyze the case of net buying interest separately from the case of net selling interest. In column 1, we find that synthetic CDO issuance significantly reduces the net buying effect, with a $R^{2}$ of $17.2 \%$. When synthetic CDO issuance doubles, the price impact from the group with big NBI is roughly $8.2 \%$ smaller, which represents about half of the average 15.7\% price increase following big CDS buying interest. Another measure of the price impact is to account for both the positive reaction to net buying and negative reaction to net selling. Hence, we take the difference in price impact and regress it on synthetic CDO issuance. The third part of the Panel A shows the regression results. Synthetic CDO issuance has a similar attenuation effect.

CDS market liquidity supply is likely correlated with liquidity supply in overall financial 
markets. In order to isolate the CDS specific funding effect, we control for variables related to general market funding demand and supply. In a volatile market, dynamic hedging incurs more transactions and hence costs. Therefore, we proxy for the market funding liquidity demand by CBOE Volatility Index (VIX). Liquidity supply of the financial market is related to the cost and ease for financial intermediaries to loan capital. We measure liquidity supply by the U.S. Treasury over Eurodollar (TED) spread. When the TED spread is high, lenders charge higher interest and funding liquidity supply is low. In Panel A of Table IX, we regress price impact on synthetic CDO issuance along with VIX and TED spread. It is shown that market funding liquidity, in particular, liquidity supply, is important for the price impact in the CDS market. However, CDS market liquidity supply has incremental power beyond variables for general market liquidity conditions in explaining the price impact.

The price impact could be autocorrelated. Funding liquidity has most power if it can explain the unexpected price impact. To examine this conjecture, we take a first-order difference to obtain the unexpected price impact. We regress this unexpected price impact on synthetic CDO issuance, VIX, and TED spread and report the regression results in Panel $\mathrm{B}$ of Table IX. The results are largely consistent with our previous finding with total price impact. When funding liquidity in the CDS market is high, unexpected price impact is low. When funding liquidity in general markets is low, CDS price impact from trading is high.

Liquidity effect tends to be short lived. The initial price impact from NBI shall be reversed and price moves back towards its fundamental value in subsequent transactions. The speed of reversal is determined by funding liquidity. We measure speed of reversal as

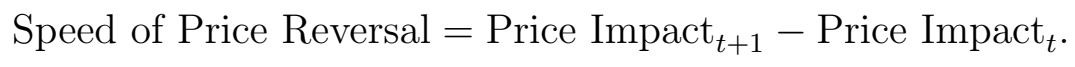

It is conceivable that informed trading induces permanent price change and its price impact will not be reversed. Hence our definition applies even if a positive price impact is followed by another positive price impact. We regress speed of price reversal on funding liquidity measures and report the findings in Panel $\mathrm{C}$ of Table IX. Our overall finding is that more funding liquidity speeds up price reversal from net CDS buying interest. Note that VIX has the strongest effect in the multivariate regressions. Hence, in a volatile environment with high liquidity demand, liquidity providers may be less willing to step in and inject liquidity. 


\section{Concluding Remarks}

Using CDS transaction data from 2002 to 2009, we show that positive buying interest between trades causes CDS spread to increase. This effect is not completely explained by delayed or concurrent information about changes in fundamentals, as represented by lagged and concurrent stock returns. Even holding stock price constant, biggest buying pressure pushes price up by $3.8 \%$ and biggest selling pressure pushes price down by 3.6\%. Big net CDS buying interest has information content. CDS spread continues to rise after initial buying activities. For CDS selling interest, the initial reaction dissipates quickly. Besides information, liquidity also underlies this effect of latent trade imbalance on CDS price changes. The net buying effect is stronger for the high bid-ask spread group than the low bid-ask spread group. It is stronger for the high immediacy demand group than the low immediacy demand group. Furthermore, net buying interest is important for the conditional relationship between CDS spread change and liquidity as for derivative contracts liquidity premium is captured by the liquidity provider who may not always be the seller.

This study sheds light on the pricing effect of CDS liquidity. Given the voluminous literature on stock, bond, and option liquidity effects, our results on CDS liquidity help to paint a more complete picture of the landscape of cross-market liquidity, which is an important challenge in the liquidity literature (Spiegel (2008)). Trading induced price movement can induce excessive CDS volatility. Future work on CDS pricing may need to take into account such impacts on liquidity and volatility. Moreover, corporate strategies may factor in the potential impact of CDS trading on its cost of debt and financial flexibility.

Our findings may have macro-prudential implications. The possibility of CDS spread increases without fundamental changes can be a concern for both issuers and regulators. The price impact and its information content suggest possible self-fulfilling vicious downward spiral for credit risk due to CDS buying. As CDS buying pushes up price, and predicts future CDS spread increase, CDS buying could breed more buying and propel CDS spread even higher. However, the evidence we have analyzed shows that at least for the corporate names in North America, this effect is mostly short lived unless it is associated with fundamental information. Hence, unless traders have private information, big price swings require a substantial amount of coordination as it is only effective for those with extremely high net buying interest. Furthermore, only high credit risk firms are susceptible to this potential threat. 


\section{References}

Acharya, Viral V., and Timothy C. Johnson, 2007, Insider trading in credit derivatives, Journal of Financial Economics 84, 110-141.

Allen, Franklin, Ana Babus, and Elena Carletti, 2009, Financial Crises: Theory and Evidence, Annual Review of Financial Economics 1, 97-116.

Allen, Franklin, and Elena Carletti, 2006, Credit Risk Transfer and Contagion, Journal of Monetary Economics 53, 89-111.

Ambrose, Brent W., Nianyun Cai, and Jean Helwege, 2010, Fallen Angels and Price Pressure, Working paper.

Amihud, Yakov, and Haim Mendelson, 1986, Asset pricing and the bid-ask spread, Journal of Financial Economics 17, 223-249.

Beber, Alessandro, Michael W. Brandt, and Kenneth A. Kavajecz, 2009, Flight-to-Quality or Flight-to-Liquidity? Evidence from the Euro-Area Bond Market, Review of Financial Studies 22, 925-957.

Blanco, Roberto, Simon Brennan, and Ian W. Marsh, 2005, An empirical analysis of the dynamic relationship between investment grade bonds and credit default swaps, Journal of Finance 60, 2255-2281.

Bollen, Nicolas P., and Robert E. Whaley, 2004, Does net buying pressure affect the shape of implied volatility functions? Journal of Finance 59, 711-754.

Bongaerts, Dion, Frank de Jong, and Joost Driessen, 2010, Derivative Pricing with Liquidity Risk: Theory and Evidence from the Credit Default Swap Market, Journal of Finance forthcoming.

Brunnermeier, Markus K., and Lasse Heje Pedersen, 2009, Market liquidity and funding liquidity, Review of Financial Studies 22, 2201-2238.

Büler, Wolfgang, and Monika Trapp, 2009, Time-Varying Credit Risk and Liquidity Premium in Bond and CDS Markets, working paper.

Cao, H. Henry, Martin D. Evans, and Richard K. Lyons, 2006, Inventory information, Journal Business 79, 325-364.

Chacko, George C., Jakub W. Jurek, and Erick Stafford, 2008, The price of immediacy, Journal of Finance 63, 1253-1290.

Chordia, Tarun, Richard Roll, and Avanidhar Subrahmanyam, 2002, Order imbalance, liquidity, and market returns, Journal of Financial Economics 65, 111-130.

Chordia, Tarun, and Avanidhar Subrahmanyam, 2004, Order Imbalance and Individual Stock Returns: Theory and Evidence, Journal of Financial Economics 72, 485-518.

Coval, Joshua A., and Erik Stafford, 2007, Asset fire sales (and purchases) in equity markets, Journal of Financial Economics 86, 479-512. 
Duffee, Gregory R., and Chunsheng Zhou, 2001, Credit derivatives in banking: Useful tools for managing risk? Journal of Monetary Economics 48, 25-54.

Duffie, Darrell, 1999, Credit swap valuation, Financial Analysts Journal, January/February, $73-87$.

Easley, David, Nicholas M. Kiefer, Maureen O'Hara, and Joseph B. Paperman, 1997, Liquidity, information, and infrequently traded stocks, Journal of Finance 51, 1405-1436.

Eberlein, Ernst, and Dilip B. Madan, 2010, Short Positions, Rally Fears and Option Markets, Applied Mathematical Finance 17, 83-98.

Ellul, Andrew, Pab Jotikasthira, and Christian T. Lundblad, 2010, Regulatory Pressure and Fire Sales in the Corporate Bond Market, Working paper.

Ericsson, Jan, Kris Jacobs, and Rodolfo Oviedo, 2009, The determinants of credit default swap premia, Journal of Financial and Quantitative Analysis 44, 109-132.

Ericsson, Jan, and Olivier Renault, 2006, Liquidity and credit risk, Journal of Finance 61, 2219-2250.

Freixas, Xavier, Gyongyi Loranth and Alan D. Morrison, 2007, Regulating Financial Conglomerates, Journal of Financial Economics 16, 479-624.

Garleanu, Nicolae, Lasse Heje Pedersen, and Allen M. Poteshman, 2009, Demand-based option pricing, Review of Financial Studies 22, 4259-4299.

Gehrig, Thomas, and Matthew Jackson, 1998, Bidask spreads with indirect competition among specialists, Journal of Financial Markets 1, 89-119.

Greenwood, Robin, and Dimitri Vayanos, 2010, Price pressure in the government bond market, American Economic Review: Papers \& Proceedings 100, 585-590.

Hendershott, Terrence, and Albert J. Menkveld, 2010, Price Pressures, Working paper.

Hendershott, Terrence, and Mark Seasholes, 2007, Market Maker Inventories and Stock Prices, American Economic Review (PEP) 97, 210-214.

Kapadia, Nikunj, and Xiaoling Pu, 2010, Limited Arbitrage between Equity and Credit Markets, Working paper.

Kraus, Alan, and Hans R. Stoll, 1972, Price Impacts of Block Trading on the New York Stock Exchange, Journal of Finance 27, 569-588.

Krishnamurthy, Arvind, and Annette Vissing-Jorgensen, 2010, The Aggregate Demand for Treasury Debt, Working paper.

Kyle, Pete, and Anna Obizhaeva, 2010, Market Microstructure Invariants, Working paper.

Lee, Charles M. C., and Mark J. Ready, 1991, Inferring Trade Direction from Intraday Data, Journal of Finance 46, 733-746.

Lippman, Steven A., and John J. McCall, 1986, An operational measure of liquidity, American Economic Review 76, 43-55. 
Longstaff, Francis, 2004, The flight to liquidity premium in U.S. Treasury bond prices, Journal Business 77, 511-526.

Longstaff, Francis A., Sanjay Mithal, and Eric Neis, 2005, Corporate yield spreads: Default risk or liquidity? New evidence from credit-default swap market, Journal of Finance 60, 2213-2253.

Minton, Bernadette A., Rene Stulz, and Rohan Williamson, 2009, How much do banks use credit derivatives to reduce risk? Journal of Financial Services Research 35, 1-35.

Pan, Jun, and Kenneth J. Singleton, 2008, Default and recovery implicit in the term structure of sovereign CDS spreads, Journal of Finance 63, 2345-2384.

Parlour, Christine A., and Guillaume Plantin, 2008, Loan sales and relationship banking, Journal of Finance 63, 1291-1314.

Pástor, Ľuboš, and Robert F. Stambaugh, 2003, Liquidity risk and expected stock returns, Journal of Political Economy 111, 642-685.

Spiegel, Matthew, 2008, Patterns in cross market liquidity, Finance Research Letters 5, 2-10.

Stulz, René M., 2004, Should we fear derivatives? Journal of Economic Perspectives 18, $173-192$.

Stulz, René M., 2010, Credit Default Swaps and the Credit Crisis, Journal of Economic Perspectives 24, 73-92.

Tang, Yongjun Dragon, and Hong Yan, 2008, Liquidity and Credit Default Swap Spreads, working paper.

Tett, Gillian, 2006, The Dream Machine: Invention of Credit Derivatives, Financial Times, March 24. 


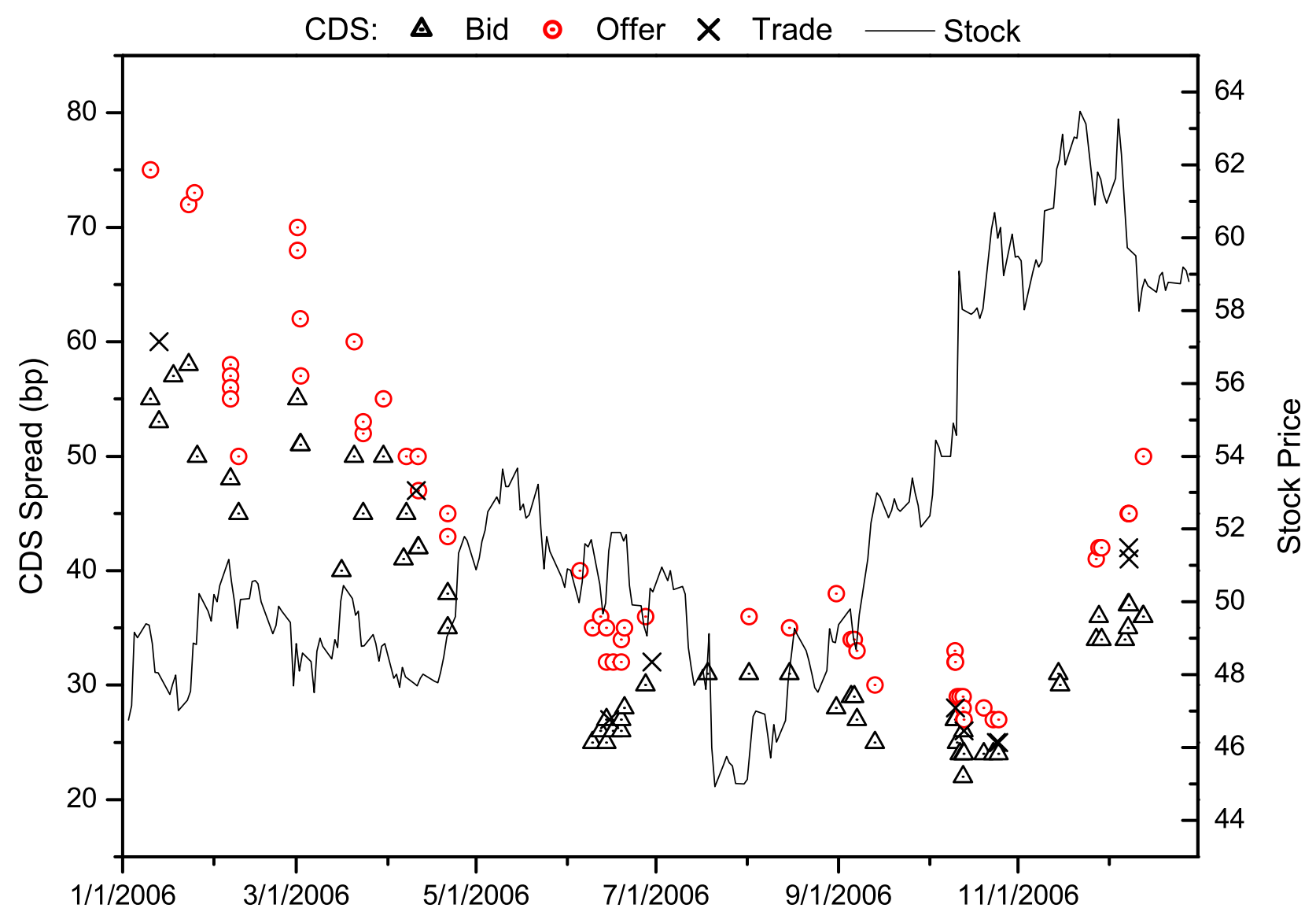

Figure 1: Activities for Yum! Brands 5-year CDS in 2006. This figure plots all the 5-year quotes and trades recorded in our dataset for Yum! Brands over the year 2006, along with its stock price. All contracts are on senior unsecured bonds denominated in U.S. Dollar. 


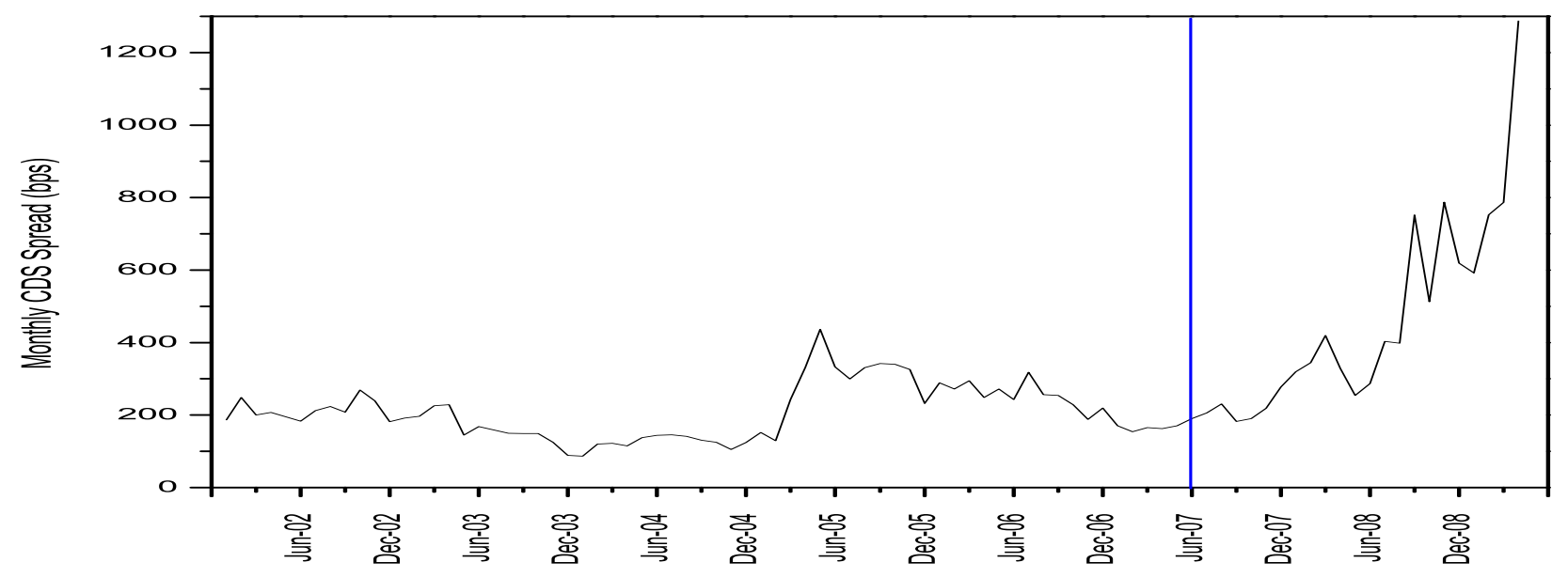

(a) Monthly CDS Spread

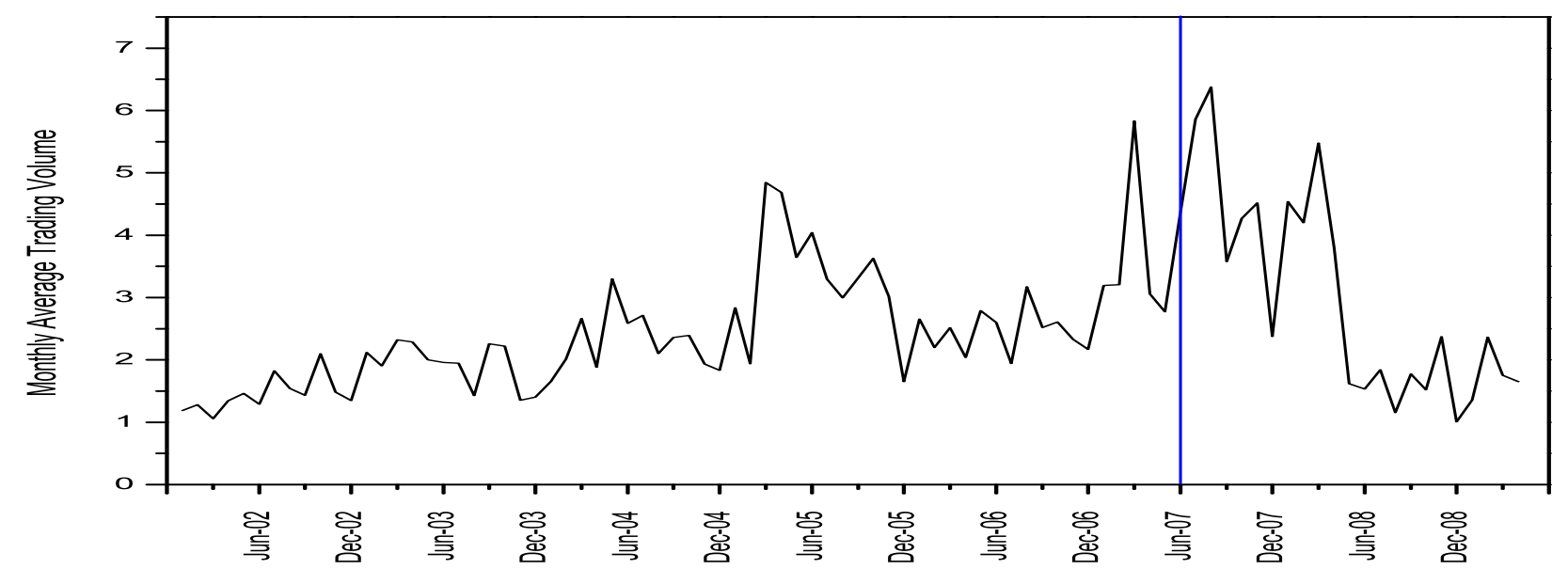

(b) Monthly Trading Volume

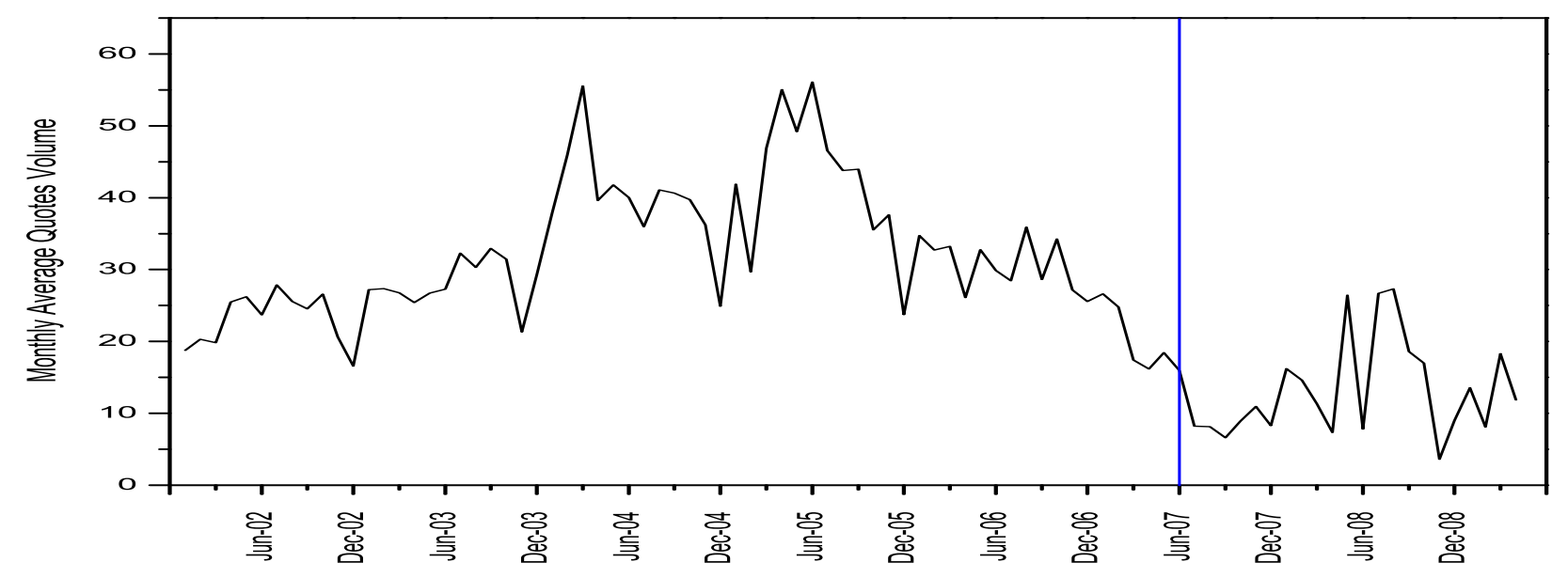

(c) Monthly Quotes Volume

Figure 2: Time Series of CDS Spread and Trading Activities. This figure plots the monthly average CDS trade spread, number of trades, and number of quotes for all firms in United States and Canada recorded in our dataset. Transactions are first aggregated to monthly average or total for each firm. Upfront CDS spreads are converted into running spreads. 

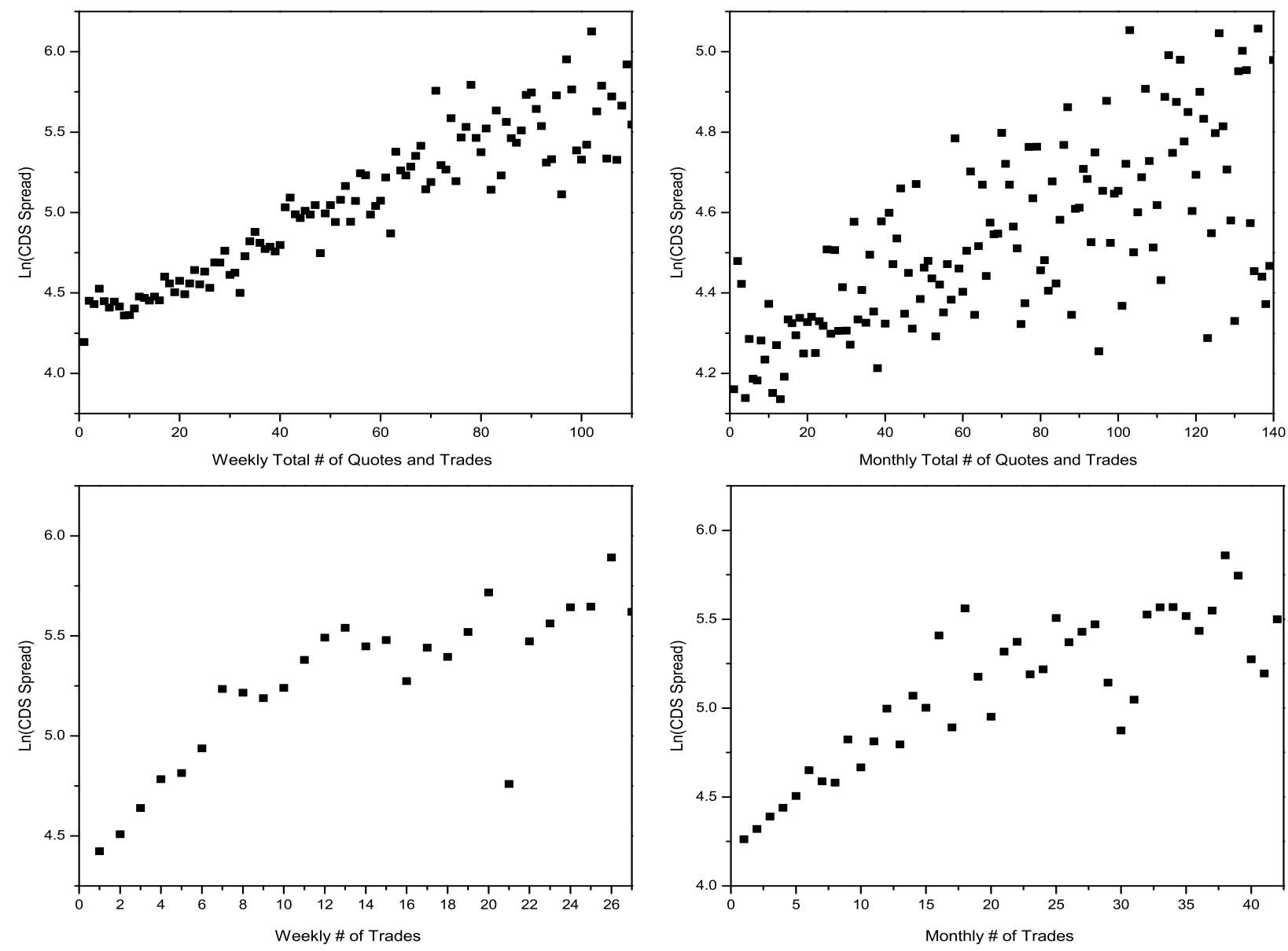

Figure 3: Weekly and Monthly CDS Transaction Measures versus Ln(CDS). This figure plots the weekly or monthly average logarithmic CDS trade spread versus weekly or monthly number of trades and total number of quotes and trades for each firm. 

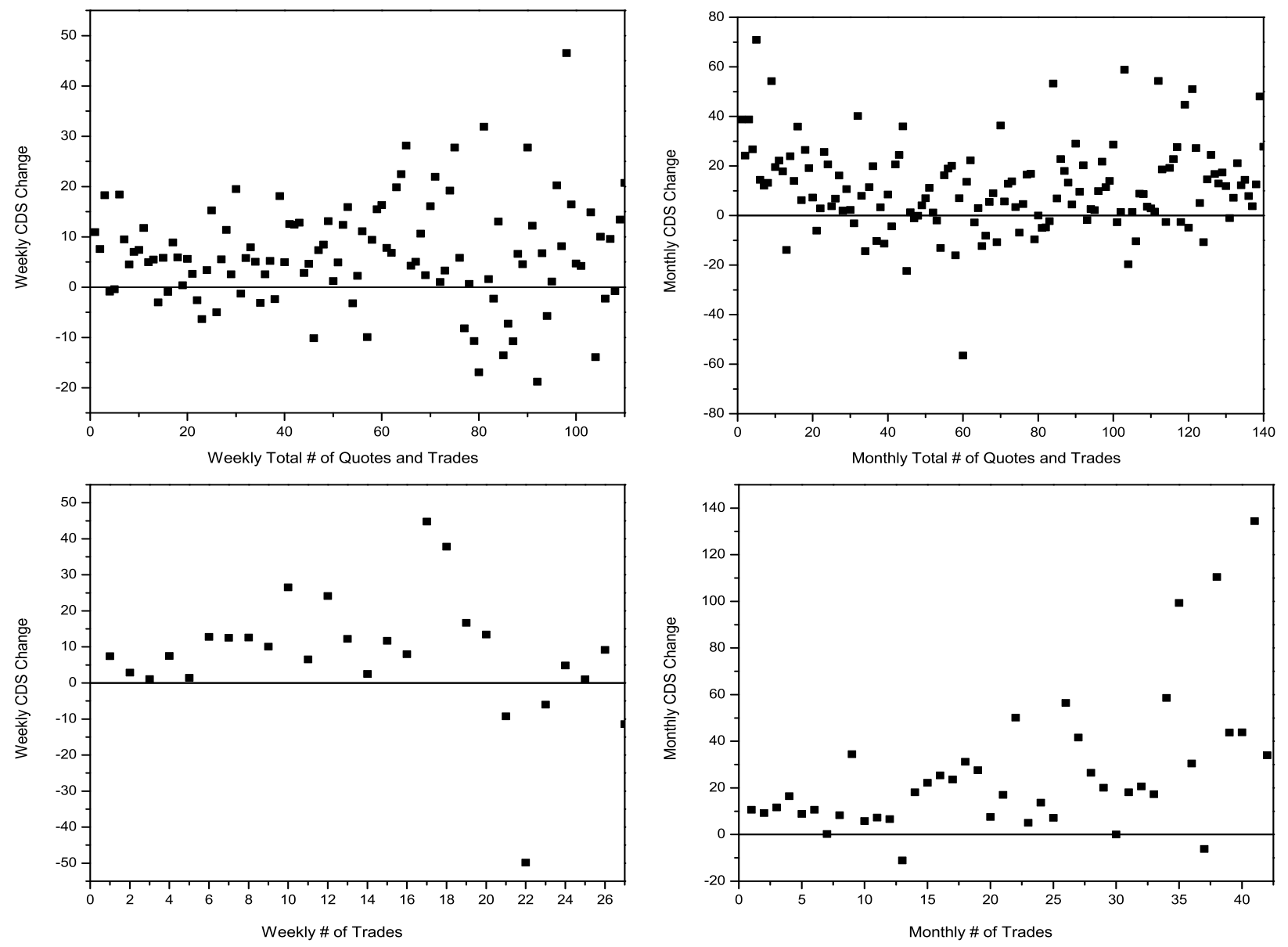

Figure 4: Weekly and Monthly CDS Transaction Measures versus CDS Price Changes. This figure plots the weekly or monthly average CDS trade price change versus weekly or monthly number of trades and total number of quotes and trades for each firm. 

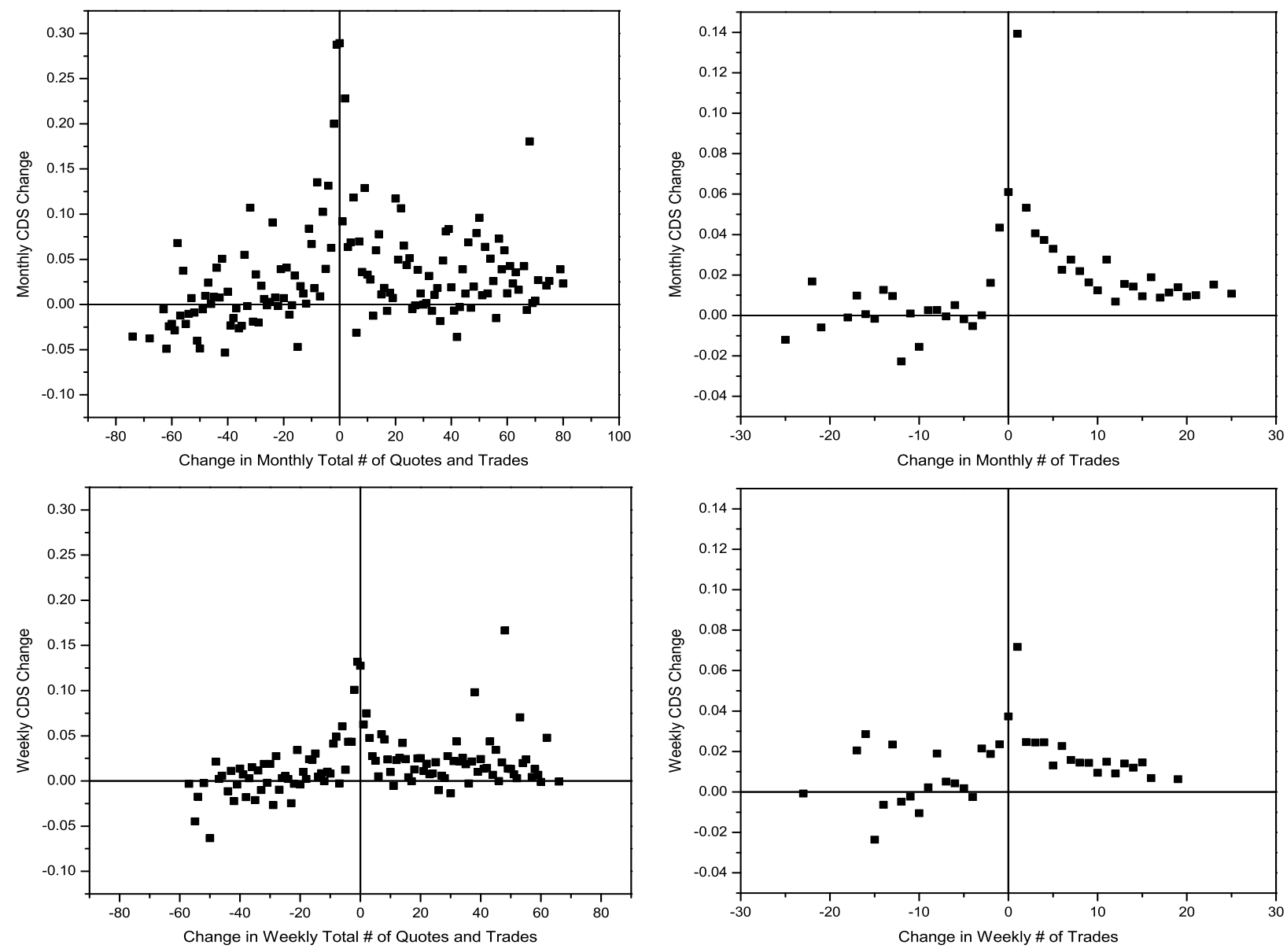

Figure 5: Weekly and Monthly Changes in CDS Transaction Measures versus CDS Price Changes. This figure plots the weekly or monthly average CDS trade price change versus weekly or monthly changes in number of trades and total number of quotes and trades for each firm. 


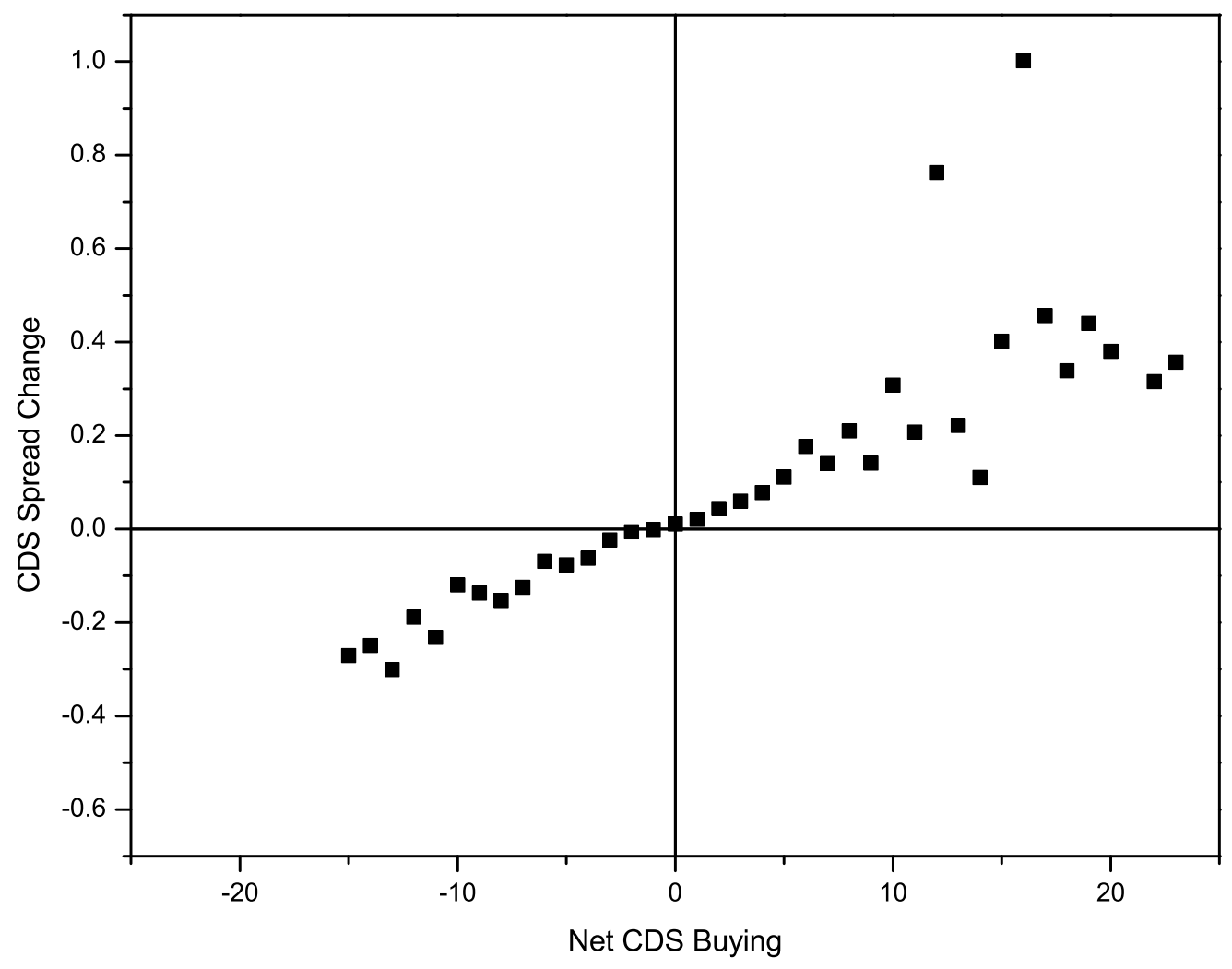

Figure 6: Net CDS Buying and CDS Price Change. This figure plots the average CDS trade price percentage change versus net CDS buying. Net CDS buying is defined as the difference between number of bids and number of offers between consecutive trades. 


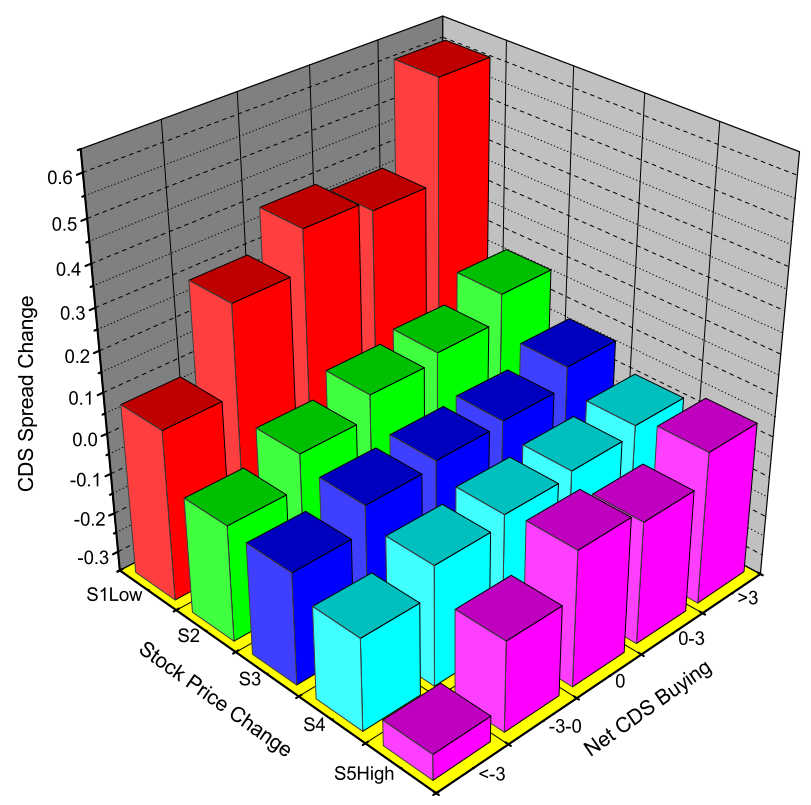

Figure 7: Net Buying, Stock Returns, and CDS Change. This figure plots the average CDS trade price percentage change categorized into twenty-five groups. These twenty-five groups are separated by net CDS buying and stock price percentage change concurrent to CDS trades. 


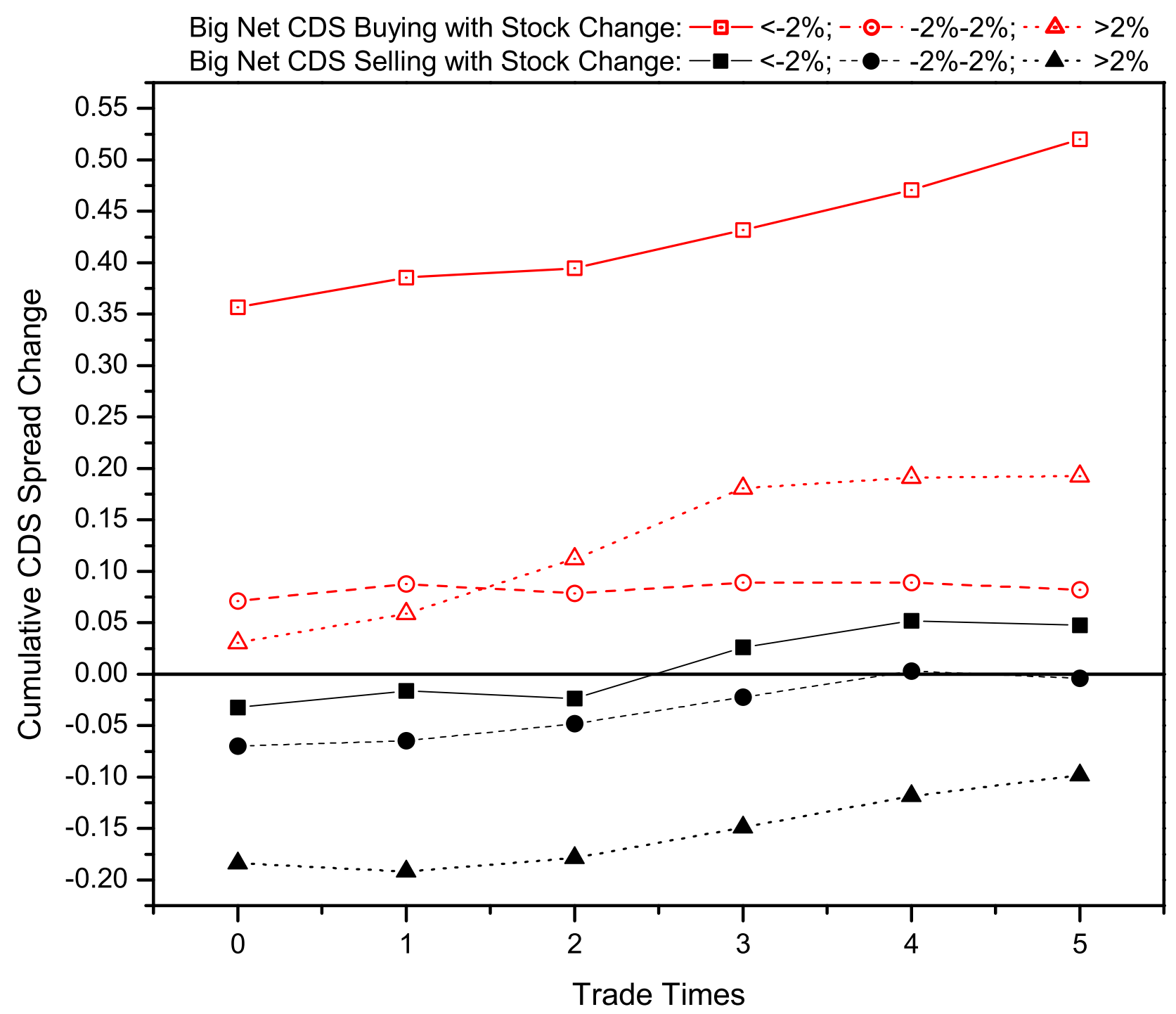

Figure 8: Cumulative CDS Spread Changes Following Big Net CDS Buying and Selling. This figure plots the cumulative changes in CDS spreads for the next five trades following the initial big net buying or selling. Each buying or selling group is further divided into three subgroups by the stock price change accompanying the net buying or selling: stock price drops $2 \%$ or more; stock price change is within $2 \%$, and stock price rises by $2 \%$ or more. 


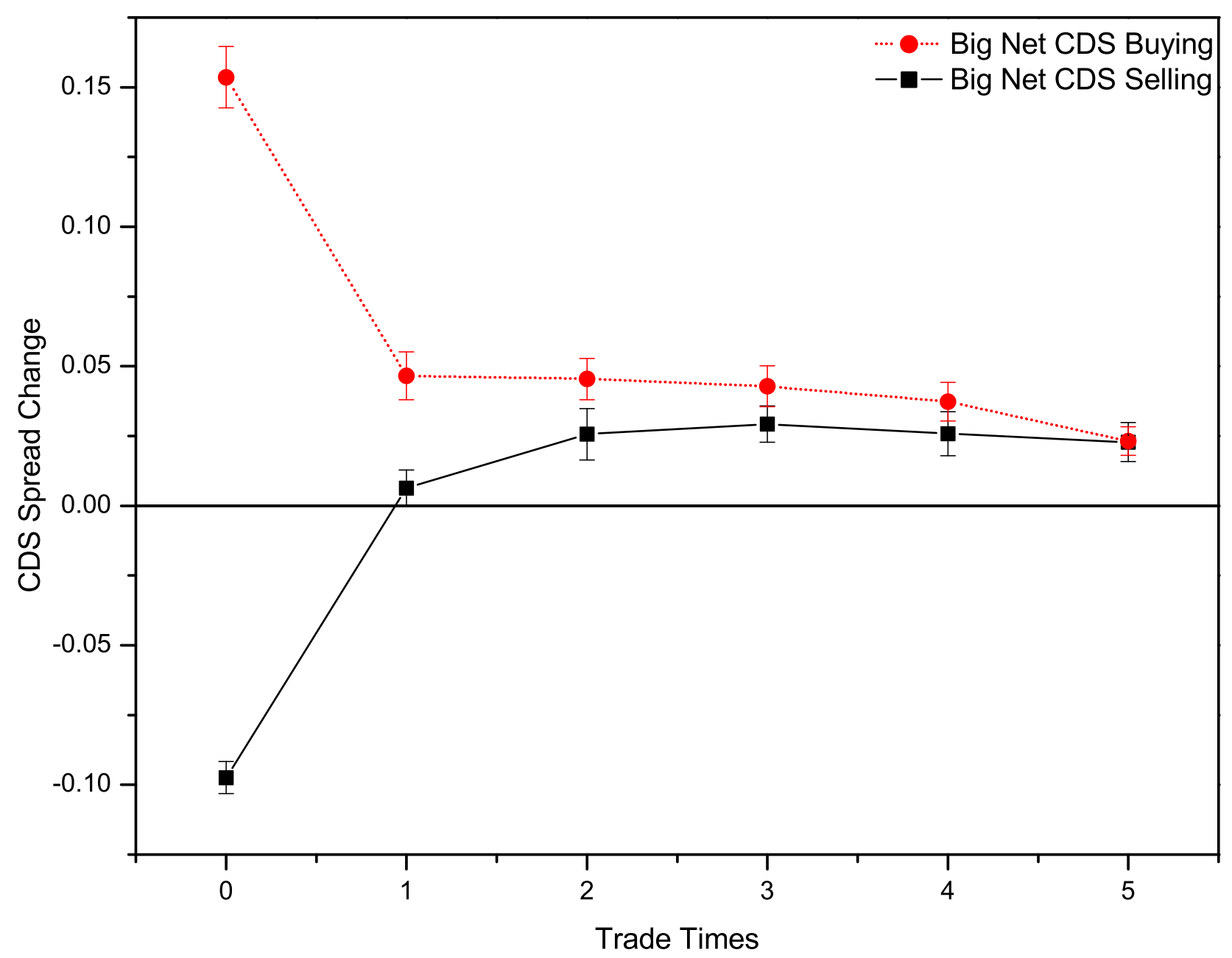

Figure 9: CDS Spread Changes Following Big Net Buying or Selling. This figure plots the CDS changes in CDS spreads for the next five trades following the initial big net buying or selling. 


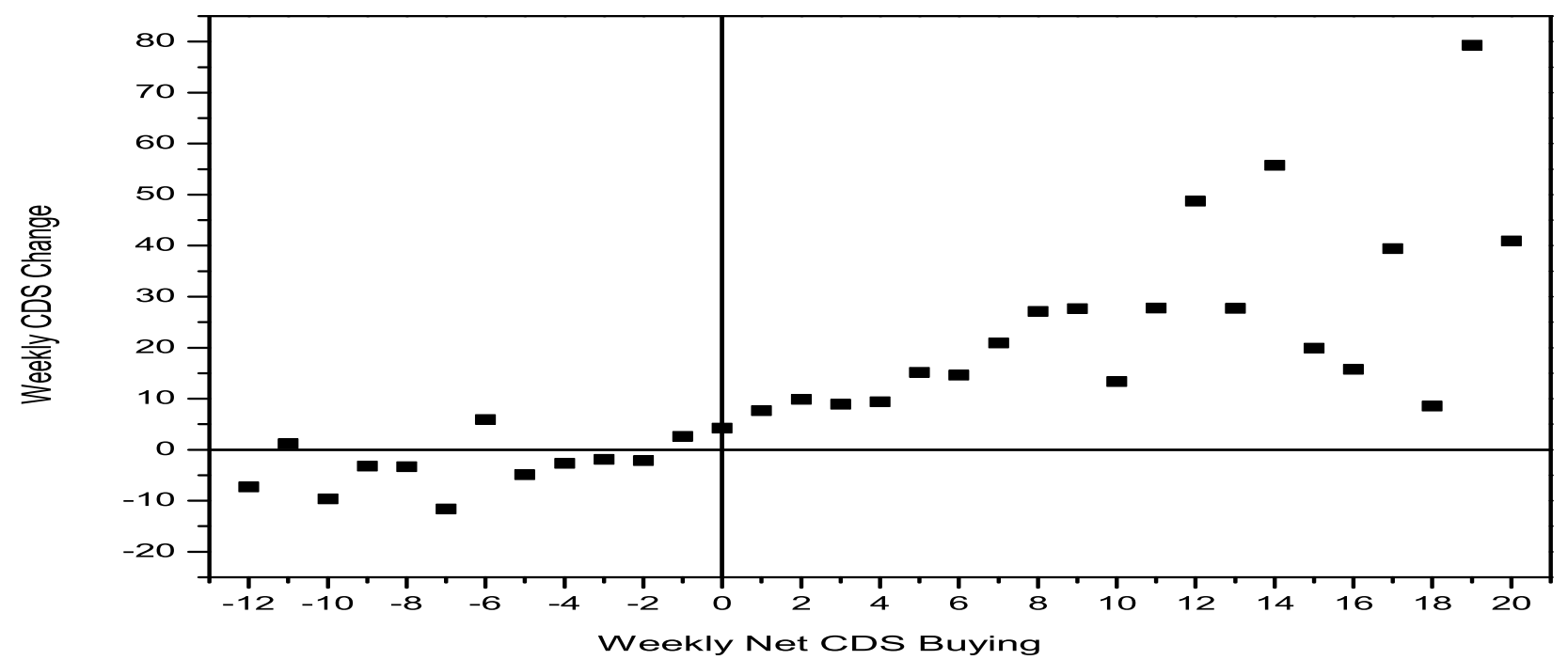

(a) Weekly

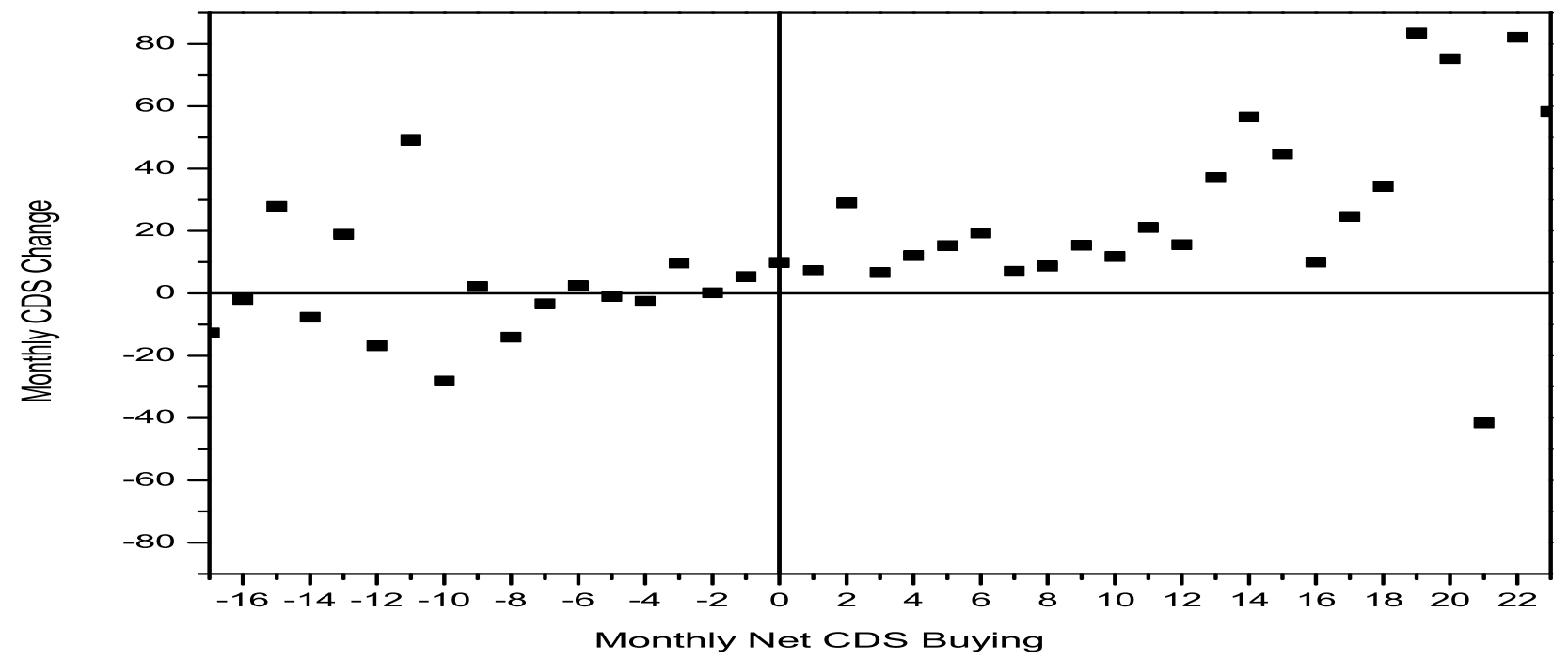

(b) Monthly

Figure 10: Weekly and Monthly Net Buying and CDS Change. This figure plots the average weekly or monthly CDS trade spread change versus weekly or monthly net CDS buying. Weekly or monthly net CDS buying is defined as the difference between total number of bids and total number of offers in one week or one month for each firm. 


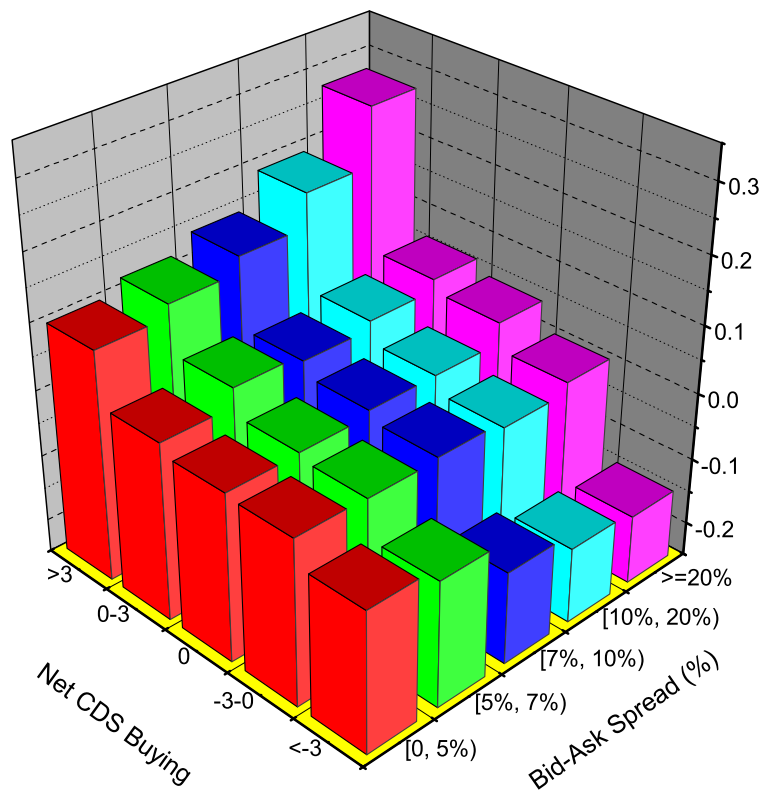

(a) Net Buying, Bid-Ask Spread, and CDS Change

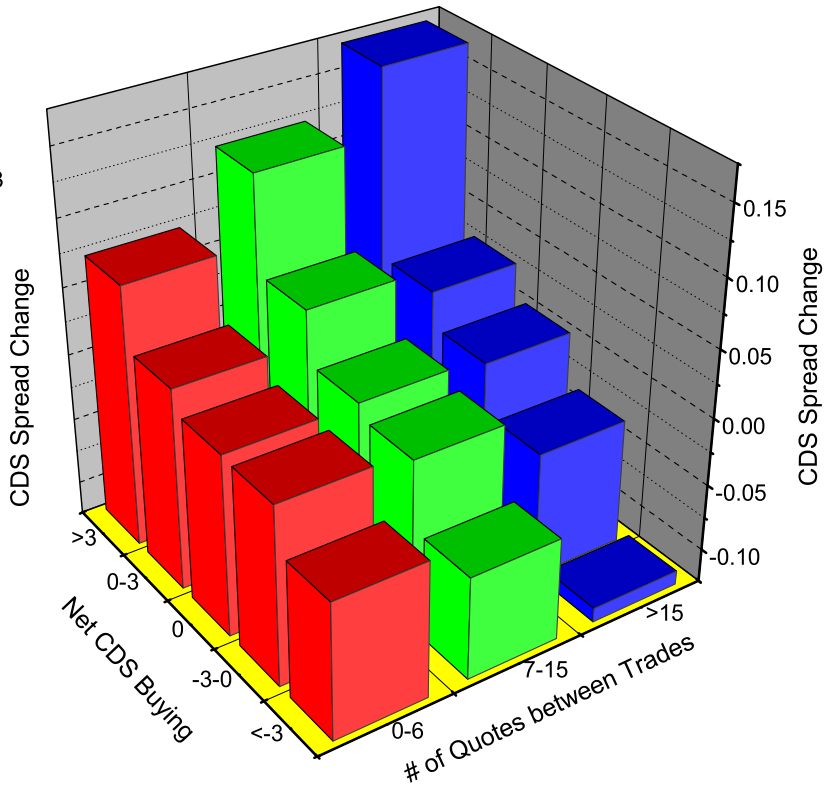

(b) Net Buying, Quotes, and CDS Change

Figure 11: Net Buying, Market Liquidity, and CDS Change. This figure plots the average CDS trade price percentage change grouped by net buying and liquidity. Net CDS buying is the difference between number of bids and number of offers between consecutive trades. Net buying is divided into five groups. Liquidity is measured by bid-ask spread in Panel (a) and number of quotes between consecutive trades in Panel (b). Liquidity is divided into five groups for bid-ask spread and three groups for number of quotes. 


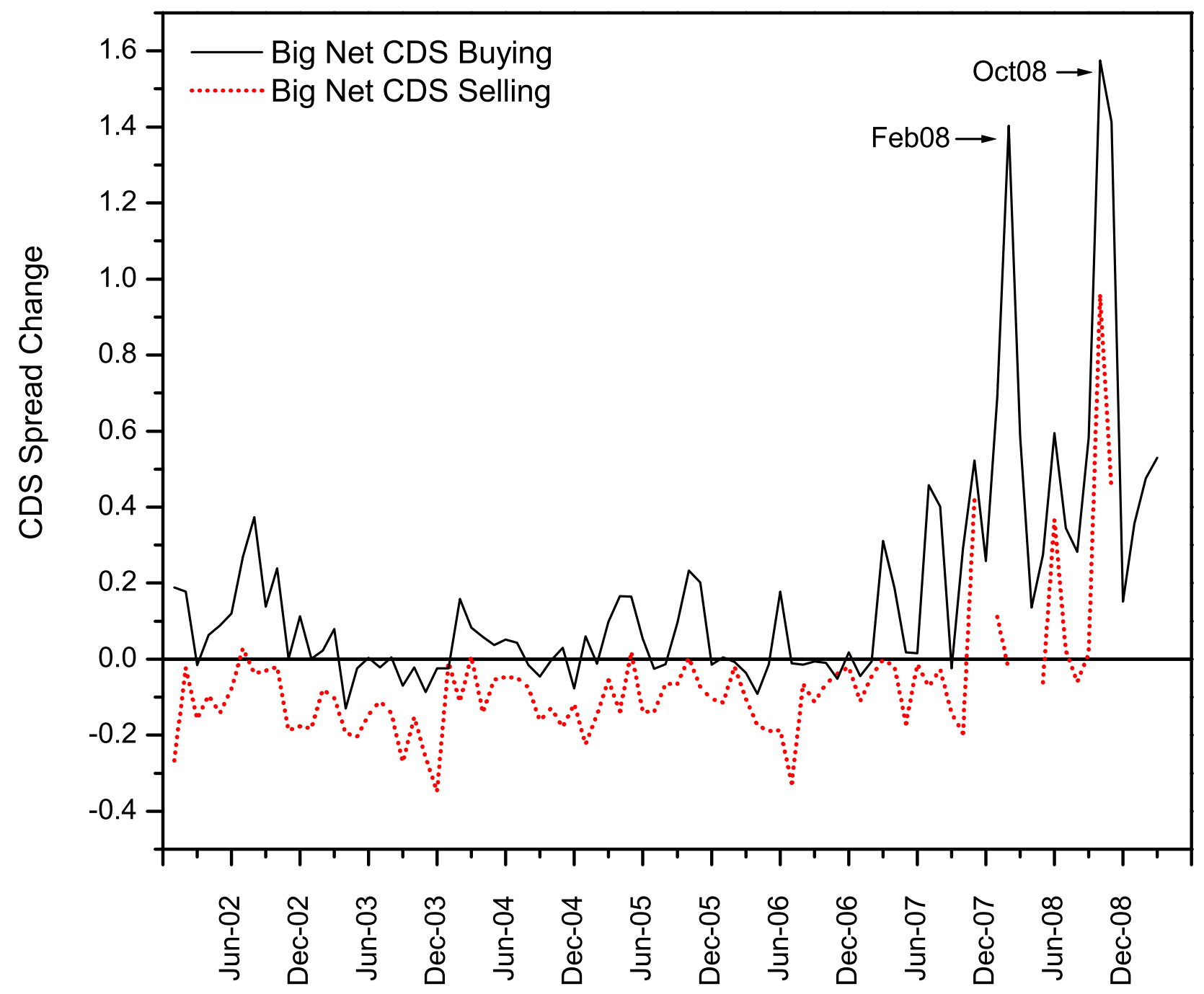

Figure 12: Time Series of Average CDS Changes Following Big Net Buying and Selling. This figure plots the monthly average CDS trade percentage change for the big net CDS buying and big net CDS selling groups. Big net CDS buying is CDS traded with net CDS buying greater than 3. And big net CDS selling is CDS traded with net CDS buying smaller than -3 . 


\section{Table I \\ Summary Statistics}

This table reports summary statistics for the entire sample used in the analysis. Panel A reports the statistics of number of bids, offers, total number of quotes, net CDS buying, bid-ask spread, average bid price, average offer price, mid-quote price and the trade percentage change between CDS trades. Net CDS buying is defined as the difference between number of bid and number of ask between trades. mid-quote price is the average of bid price and offer price which occurred at the same time. Bid-ask spread(difference) in basic points term is defined as the difference between offer price and bid price which occurred at the same time. Bid-ask spread in percentage term is the difference of offer and bid price over the mid-quote price. Trade price change is defined as the percentage change to the last trade price. Panel B reports the statistics of firm characteristics for COMPUSTAT and CRSP linked CDS firms at firm-monthly level. Leverage is defined as long-term debt over market value of total assets. Size is defined as logarithmic market value of total assets. Profitability ratio is defined as net income over market value of total assets. Cash ratio is defined as cash and cash equivalent over market value of total assets. EDF (Expected Default Frequency) is calculated by KMV-Merton Model. CDS/Bond basis is defined as the difference between monthly CDS trade price and bond excess yield over 5 -year treasury rate. Bond yield data are from TRACE.

Panel A: Summary Statistics of CDS Transactions

\begin{tabular}{lrrrrrr}
\hline Variable & $\mathrm{N}$ & Mean & Median & StdDev & Min & Max \\
\hline Duration between trades (days) & 54654 & 14.29 & 0.212 & 70.25 & 0.000 & 2187.9 \\
\# of Bid & 55341 & 5.725 & 1.000 & 10.61 & 0 & 212.0 \\
\# of Offer & 55341 & 5.229 & 1.000 & 9.711 & 0 & 165.0 \\
\# of Quotes & 55341 & 10.95 & 2.000 & 20.14 & 0 & 364.0 \\
Net CDS Buying & 55341 & 0.496 & 0 & 2.824 & -54.00 & 85.00 \\
Bid-Ask Spread (difference, bps) & 55341 & 14.01 & 6.000 & 36.94 & -350.4 & 2934.6 \\
Bid-Ask Spread (\%) & 55341 & 9.141 & 7.143 & 8.561 & 0 & 142.9 \\
Average of Mid-quote (bps) & 34285 & 245.9 & 149.1 & 293.3 & 3.000 & 7528.1 \\
Average of Bid Price (bps) & 39344 & 246.2 & 149.7 & 296.2 & 2.000 & 7058.2 \\
Average of Ask Price (bps) & 37300 & 255.7 & 160.0 & 300.7 & 4.500 & 7528.1 \\
Trade Price Change (\%) & 54794 & 2.088 & 0 & 26.53 & -92.21 & 1275.0 \\
\hline
\end{tabular}

Panel B: Summary Statistics of Firm Characteristics

\begin{tabular}{lrrrrrr}
\hline Variable & $\mathrm{N}$ & Mean & Median & StdDev & Min & Max \\
\hline Monthly Stock Volatility & 52202 & 0.023 & 0.017 & 0.023 & 0 & 2.317 \\
Leverage & 49618 & 0.496 & 0.475 & 0.229 & 0.010 & 1.000 \\
Size & 49618 & 9.532 & 9.340 & 1.377 & 4.425 & 14.72 \\
Profitability Ratio & 49594 & 0.004 & 0.007 & 0.030 & -1.097 & 0.384 \\
Cash Ratio & 49581 & 0.055 & 0.031 & 0.066 & 0 & 0.840 \\
EDF & 35494 & 3.752 & 0.010 & 9.800 & 0.010 & 35.00 \\
CDS/Bond Basis (b.p.) & 23550 & -135.5 & -22.9 & 326.1 & -6386.8 & 1402.7 \\
\hline
\end{tabular}




\section{Table II \\ Net CDS Buying and CDS Spread Change}

This table reports the average CDS trade price percentage change grouped by net CDS buying. Net CDS buying is the difference between number of bids and number of offers between consecutive trades. First column report full sample results. Second column covers trades occured within one day. Third column covers reference issuers rated BBB. Fourth column limit the sample with CDS/Bond basis within 100 basis points. CDS/Bond basis is the difference between CDS spread and the bond yield spread using transaction data from TRACE.

\begin{tabular}{lrrrr}
\hline & Full Sample & $\begin{array}{c}\text { Duration } \\
<1 \text { day }\end{array}$ & $\begin{array}{c}\text { Credit Rating } \\
=\text { BBB }\end{array}$ & $\begin{array}{c}\text { CDS/Bond Basis } \\
\in[-100,100]\end{array}$ \\
\hline Net CDS Buying $<-3$ & -0.095 & -0.011 & -0.094 & -0.056 \\
Net CDS Buying $\in[-3,0)$ & -0.004 & -0.002 & -0.012 & 0.012 \\
Net CDS Buying=0 & 0.011 & 0.003 & 0.008 & 0.011 \\
Net CDS Buying $\in(0,3]$ & 0.033 & 0.011 & 0.029 & 0.018 \\
Net CDS Buying $>3$ & 0.157 & 0.039 & 0.141 & 0.165 \\
\hline Net CDS Buying $(>3)-(<-3)$ & 0.253 & 0.051 & 0.235 & 0.221 \\
(t-stat) & $(20.23)$ & $(5.48)$ & $(13.69)$ & $(2.92)$ \\
\hline
\end{tabular}




\section{Table III}

\section{Net CDS Buying and CDS Spread Change: Controlling for Stock Return}

This table reports average CDS trade price percentage change grouped by net CDS buying and stock return. Panel A controls for concurrent stock return defined as the stock price percentage change between CDS trades. Panel B controls for lagged 5-day stock return which is the cumulative stock return for five days before the CDS trade.

Panel A: Concurrent Stock Return

\begin{tabular}{|c|c|c|c|c|c|c|c|}
\hline \multirow[b]{3}{*}{ Net CDS Buying <-3 } & \multicolumn{5}{|c|}{ Concurrent Stock Return } & \multirow{2}{*}{\multicolumn{2}{|c|}{$(>2 \%)-(<-2 \%)$}} \\
\hline & $(<-2 \%)$ & {$[-2 \%,-0.1 \%)$} & {$[-0.1 \%, 0.1 \%]$} & $(0.1 \%, 2 \%]$ & $(>2 \%)$ & & \\
\hline & -0.032 & -0.053 & -0.036 & -0.093 & -0.184 & -0.152 & $(-7.72)$ \\
\hline Net CDS Buying $\in[-3,0)$ & 0.064 & -0.003 & 0.001 & -0.022 & -0.069 & -0.133 & $(-9.40)$ \\
\hline Net CDS Buying $=0$ & 0.133 & 0.019 & 0.003 & 0.009 & -0.030 & -0.163 & $(-8.36)$ \\
\hline Net CDS Buying $\in(0,3]$ & 0.154 & 0.027 & 0.008 & 0.018 & -0.013 & -0.168 & $(-11.01)$ \\
\hline Net CDS Buying $>3$ & 0.357 & 0.089 & 0.038 & 0.058 & 0.030 & -0.326 & $(-9.49)$ \\
\hline $\begin{array}{l}\text { Net CDS Buying } \\
(>3)-(<-3) \text { (t-stat) }\end{array}$ & $\begin{array}{r}0.389 \\
(11.59)\end{array}$ & $\begin{array}{r}0.142 \\
(6.54)\end{array}$ & $\begin{array}{r}0.075 \\
(2.46)\end{array}$ & $\begin{array}{r}0.150 \\
(7.47)\end{array}$ & $\begin{array}{r}0.215 \\
(10.22)\end{array}$ & & \\
\hline
\end{tabular}

Panel B: Lagged 5-Day Stock Return

\begin{tabular}{|c|c|c|c|c|c|c|c|}
\hline & \multicolumn{5}{|c|}{ Lagged 5-day Stock Return } & \multirow{2}{*}{\multicolumn{2}{|c|}{$(>5 \%)-(<-5 \%)$}} \\
\hline & $(<-5 \%)$ & {$[-5 \%,-1 \%)$} & {$[-1 \%, 1 \%]$} & $(1 \%, 5 \%]$ & $(>5 \%)$ & & \\
\hline Net CDS Buying $<-3$ & 0.010 & -0.122 & -0.157 & -0.123 & -0.120 & -0.131 & $(-4.35)$ \\
\hline Net CDS Buying $\in[-3,0)$ & 0.044 & -0.007 & -0.016 & -0.022 & -0.029 & -0.072 & $(-5.98)$ \\
\hline Net CDS Buying $=0$ & 0.030 & 0.019 & 0.009 & -0.002 & 0.006 & -0.024 & $(-2.26)$ \\
\hline Net CDS Buying $\in(0,3]$ & 0.076 & 0.030 & 0.035 & 0.020 & 0.032 & -0.044 & $(-2.65)$ \\
\hline Net CDS Buying $>3$ & 0.363 & 0.150 & 0.103 & 0.123 & 0.184 & -0.179 & $(-2.65)$ \\
\hline $\begin{array}{l}\text { Net CDS Buying } \\
(>3)-(<-3) \text { (t-stat) }\end{array}$ & $\begin{array}{l}0.352 \\
(6.32)\end{array}$ & $\begin{array}{r}0.271 \\
(10.81)\end{array}$ & $\begin{array}{l}0.259 \\
(9.22)\end{array}$ & $\begin{array}{l}0.245 \\
(8.40)\end{array}$ & $\begin{array}{l}0.304 \\
(6.26)\end{array}$ & & \\
\hline
\end{tabular}




\section{Table IV}

\section{Net CDS Buying and CDS Spread Change Regression}

This table reports the regression result of CDS trade percentage change on net CDS buying, concurrent stock return, lagged 5-day stock return, lagged net CDS buying, and control variables. Term Slope is the difference between 10-year and 2-year treasury rates.

\begin{tabular}{|c|c|c|c|c|c|c|}
\hline Variable & $(1)$ & $(2)$ & $(3)$ & $(4)$ & $(5)$ & $(6)$ \\
\hline \multirow[t]{2}{*}{ Intercept } & $0.015^{* * *}$ & $-0.056^{* * *}$ & $-0.047^{* * *}$ & $-0.052^{* * *}$ & $-0.054^{* * *}$ & $-0.043^{* * *}$ \\
\hline & $(8.76)$ & $(-3.43)$ & $(-2.89)$ & $(-3.20)$ & $(-3.32)$ & $(-2.66)$ \\
\hline \multirow[t]{2}{*}{ Net CDS Buying } & $0.019^{* * *}$ & $0.015^{* * *}$ & $0.014^{* * *}$ & $0.015^{* * *}$ & $0.015^{* * *}$ & $0.015^{* * *}$ \\
\hline & $(31.92)$ & $(27.94)$ & $(27.60)$ & $(27.91)$ & $(28.01)$ & $(27.65)$ \\
\hline \multirow[t]{2}{*}{ Concurrent Stock Return } & . & . & $-0.324^{* * *}$ & . & . & $-0.317^{* * *}$ \\
\hline & $\cdot$ & . & $(-20.26)$ & $\cdot$ & $\cdot$ & $(-19.67)$ \\
\hline \multirow[t]{2}{*}{ Lagged 5-day Stock Return } & . & $\cdot$ &. & $-0.101^{* * *}$ & . & $-0.065^{* * *}$ \\
\hline & . & $\cdot$ & . & $(-6.26)$ & & $(-4.03)$ \\
\hline \multirow[t]{2}{*}{ Lagged Net CDS Buying } & . & . & . & r & $-0.001^{* *}$ & $-0.001^{* *}$ \\
\hline & $\cdot$ & & & & $(-2.39)$ & $(-2.32)$ \\
\hline \multirow[t]{2}{*}{$\Delta$ Stock Volatility } & . & $1.579^{* * *}$ & $1.516^{* * *}$ & $1.578^{* * *}$ & $1.580^{* * *}$ & $1.517^{* * *}$ \\
\hline & . & $(91.46)$ & $(86.92)$ & $(91.41)$ & $(91.50)$ & $(87.00)$ \\
\hline \multirow[t]{2}{*}{$\Delta$ Leverage } & . & $0.949^{* * *}$ & $0.839^{* * *}$ & $0.942^{* * *}$ & $0.950^{* * *}$ & $0.837^{* * *}$ \\
\hline & . & $(30.49)$ & $(26.69)$ & $(30.24)$ & $(30.50)$ & $(26.63)$ \\
\hline \multirow[t]{2}{*}{$\Delta$ Size } & r & -0.087 & $1.520^{* * *}$ & 0.003 & -0.080 & $1.547^{* * *}$ \\
\hline & . & $(-0.28)$ & $(4.84)$ & $(0.01)$ & $(-0.26)$ & $(4.92)$ \\
\hline \multirow[t]{2}{*}{$\Delta$ Profitablity Ratio } & . & -0.000 & -0.000 & -0.000 & -0.000 & -0.000 \\
\hline & . & $(-1.51)$ & $(-1.47)$ & $(-1.53)$ & $(-1.52)$ & $(-1.49)$ \\
\hline \multirow[t]{2}{*}{$\Delta$ Cash Ratio } & . & 0.002 & $0.003^{*}$ & 0.002 & 0.002 & $0.003^{*}$ \\
\hline & . & $(1.53)$ & $(1.77)$ & $(1.54)$ & $(1.53)$ & $(1.78)$ \\
\hline \multirow[t]{2}{*}{ 5-Year Swap Rate } & . & $0.013^{* * *}$ & $0.011^{* * *}$ & $0.012^{* * *}$ & $0.012^{* * *}$ & $0.010^{* * *}$ \\
\hline & · & (3.96) & (3.49) & (3.72) & (3.88) & $(3.27)$ \\
\hline \multirow{2}{*}{ Term Slope } & . & $0.009^{* * *}$ & $0.007^{* * *}$ & $0.008^{* * *}$ & $0.009^{* * *}$ & $0.007^{* *}$ \\
\hline & . & (3.31) & $(2.74)$ & $(2.87)$ & (3.29) & $(2.45)$ \\
\hline$\overline{\mathrm{N}}$ & 30967 & 30967 & 30967 & 30967 & 30967 & 30967 \\
\hline $\mathrm{F}$ & 1019.0 & 1548.0 & 1439.8 & 1382.1 & 1376.9 & 1180.8 \\
\hline Adj R-Sq & 0.0318 & 0.2855 & 0.2949 & 0.2864 & 0.2856 & 0.2953 \\
\hline
\end{tabular}




\section{Table V \\ Two-Stage Simultaneous Equations}

This table reports results from a two-stage regression of CDS trade percentage change on net buying interest and control variables. Term Slope is the difference between 10-year and 2-year treasury rates.

\begin{tabular}{|c|c|c|c|}
\hline Stage & Variable & Estimate & t-value \\
\hline \multirow{15}{*}{ I: $\Delta$ CDS Spread } & Intercept & -0.0379 & $(-2.54)$ \\
\hline & Lagged $\Delta$ CDS Spread & -0.0273 & $(-5.71)$ \\
\hline & Net CDS Buying & 0.0131 & $(3.94)$ \\
\hline & Concurrent Stock Return & -0.1430 & $(-9.74)$ \\
\hline & Lagged 5-day Stock Return & -0.0772 & $(-5.80)$ \\
\hline & $\Delta$ Stock Volatility & 1.4637 & $(84.02)$ \\
\hline & $\Delta$ Leverage & 1.2198 & $(41.63)$ \\
\hline & $\Delta$ Size & 0.5511 & $(1.93)$ \\
\hline & $\Delta$ Profitability Ratio & -0.0003 & $(-2.10)$ \\
\hline & $\Delta$ Cash Ratio & 0.0023 & $(1.59)$ \\
\hline & 5-Year Swap Rate & 0.0088 & $(3.13)$ \\
\hline & Term Slope & 0.0055 & $(2.38)$ \\
\hline & $\mathrm{N}$ & 30142 & \\
\hline & $\mathrm{F}$ & 1481.5 & \\
\hline & Adjusted R-Sq & 0.3508 & \\
\hline \multirow[t]{8}{*}{ II: Net CDS Buying } & Intercept & 0.4160 & $(26.98)$ \\
\hline & $\Delta$ CDS Spread & 1.4758 & (13.49) \\
\hline & Concurrent Stock Return & -0.0533 & $(-0.31)$ \\
\hline & Lagged 5-day Stock Return & -0.0446 & $(-0.27)$ \\
\hline & Lagged Net CDS Buying & 0.1319 & $(24.34)$ \\
\hline & $\mathrm{N}$ & 30142 & \\
\hline & $\mathrm{F}$ & 214.1 & \\
\hline & Adjusted R-Sq & 0.0275 & \\
\hline
\end{tabular}




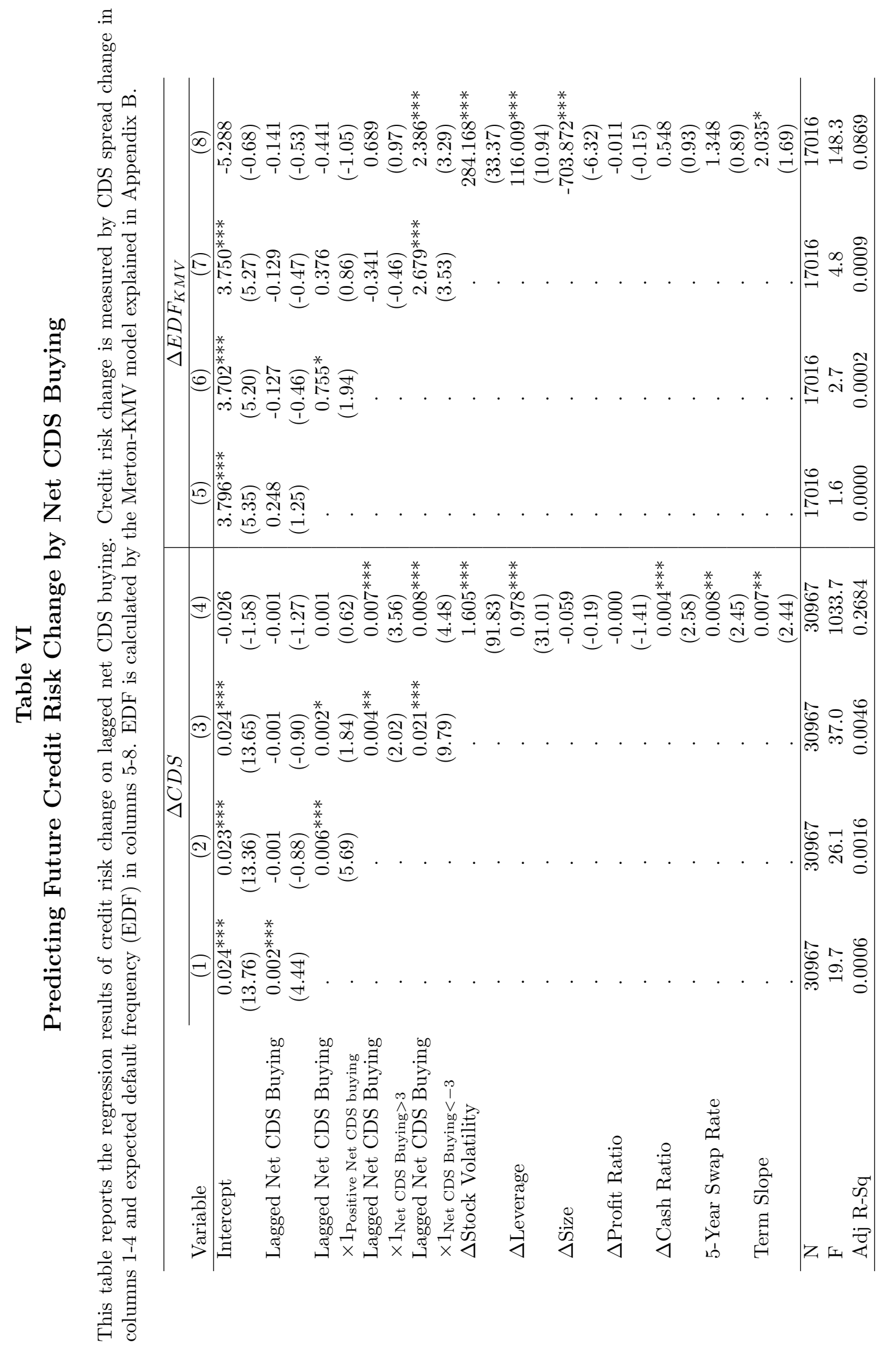


Table VII

\section{Net CDS Buying, Market Liquidity, and CDS Spread Change}

This table reports average CDS trade price percentage change grouped by net CDS buying and CDS market liquidity. Liquidity is measured by bid-ask spread in Panel A and demand for immediacy (number of quotes between consecutive trades) in Panel B.

Panel A: Liquidity Measured by Bid-Ask Spread

\begin{tabular}{lrrrrr|rr}
\hline & \multicolumn{3}{c|}{ Bid-Ask Spread } & \multicolumn{2}{c}{$(\geq 20 \%)-(<5 \%)$} \\
\hline Net CDS Buying $<-3$ & $-0.039)$ & -0.061 & -0.112 & -0.137 & -0.147 & -0.108 & $(-4.96)$ \\
Net CDS Buying $\in[-3,0)$ & -0.001 & -0.004 & -0.001 & -0.012 & 0.002 & 0.004 & $(0.21)$ \\
Net CDS Buying=0 & 0.003 & 0.005 & 0.012 & 0.012 & 0.043 & 0.040 & $(4.65)$ \\
Net CDS Buying $\in(0,3]$ & 0.017 & 0.044 & 0.033 & 0.044 & 0.060 & 0.043 & $(3.41)$ \\
Net CDS Buying $>3$ & 0.097 & 0.116 & 0.139 & 0.188 & 0.274 & 0.177 & $(4.19)$ \\
\hline Net CDS Buying & 0.137 & 0.177 & 0.251 & 0.326 & 0.422 & & \\
$(>3)-(<-3)$ (t-stat) & $(7.01)$ & $(8.24)$ & $(9.35)$ & $(11.79)$ & $(9.74)$ & & \\
\hline
\end{tabular}

Panel B: Liquidity Measured by Demand for Immediacy

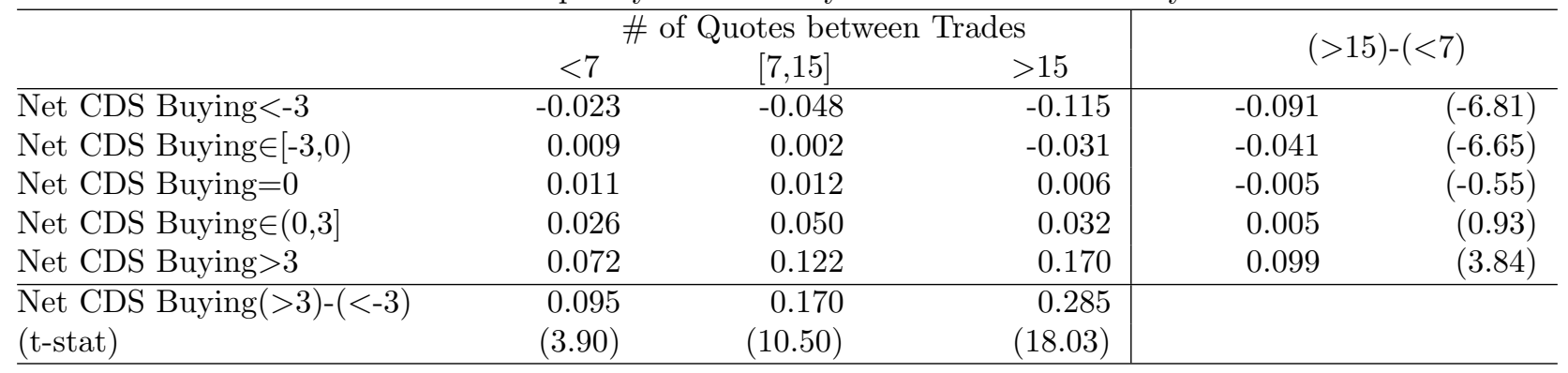


Table VIII

Net CDS Buying and CDS Spread Change: Conditioning on Market Liquidity

This table reports the regression results of CDS trade percentage change on net CDS buying, and conditioning variables defined by CDS market liquidity including bid-ask spread and number of quotes between consecutive trades. Net CDS buying is the difference between number of bids and number of offers between consecutive trades.

\begin{tabular}{|c|c|c|c|c|}
\hline$\overline{\text { Variable }}$ & (1) & $(2)$ & $(3)$ & (4) \\
\hline \multirow[t]{2}{*}{$\overline{\text { Intercept }}$} & $0.0152^{* * *}$ & $0.0155^{* * *}$ & $0.0157^{* * *}$ & $-0.0383^{* *}$ \\
\hline & $(8.91)$ & $(9.07)$ & $(9.17)$ & $(-2.36)$ \\
\hline \multirow[t]{2}{*}{ Net CDS Buying } & $0.0175^{* * *}$ & $0.0104^{* * *}$ & $0.0092^{* * *}$ & $0.0059^{* * *}$ \\
\hline & (19.12) & $(4.71)$ & $(4.06)$ & $(3.05)$ \\
\hline \multirow{2}{*}{$\begin{array}{l}\text { Net CDS Buying } \\
\times 1_{(\text {Bid-Ask Spread }>10 \%)}\end{array}$} & $0.0033^{* * *}$ & . & $0.0029^{* *}$ & $0.0029^{* * *}$ \\
\hline & $(2.76)$ & . & $(2.42)$ & $(2.81)$ \\
\hline \multirow{2}{*}{$\begin{array}{l}\text { Net CDS Buying } \\
\times 1_{(\text {Quotes } \#>7)}\end{array}$} & . & $0.0096^{* * *}$ & $0.0091^{* * *}$ & $0.0072^{* * *}$ \\
\hline & . & $(4.17)$ & $(3.95)$ & $(3.65)$ \\
\hline \multirow[t]{2}{*}{ Concurrent Stock Return } & . & . & . & $-0.3105^{* * *}$ \\
\hline & . & . & . & $(-19.26)$ \\
\hline \multirow[t]{2}{*}{ Lagged 5-day Stock Return } & . & . & . & $-0.0669^{* * *}$ \\
\hline & . & . & . & $(-4.15)$ \\
\hline \multirow[t]{2}{*}{$\Delta$ Stock Volatility } & . & . & . & $1.4949^{* * *}$ \\
\hline & . & . & . & $(86.09)$ \\
\hline \multirow[t]{2}{*}{$\Delta$ Leverage } & . & . & . & $0.9094^{* * *}$ \\
\hline & . & . & . & $(28.95)$ \\
\hline \multirow[t]{2}{*}{$\Delta$ Size } & . & . & . & $1.7861^{* * *}$ \\
\hline & $\cdot$ & r. & . & $(5.69)$ \\
\hline \multirow{2}{*}{$\Delta$ Profit Ratio } & . & . & . & -0.0003 \\
\hline & $\cdot$ & r. & r. & $(-1.44)$ \\
\hline \multirow[t]{2}{*}{$\Delta$ Cash Ratio } & . & . & . & $0.0027^{*}$ \\
\hline & r. & r. & r. & (1.69) \\
\hline \multirow[t]{2}{*}{ 5-Year Swap Rate } & . & . & . & $0.0094^{* * *}$ \\
\hline & r. & . & . & (2.98) \\
\hline \multirow[t]{2}{*}{ Term Slope } & . & . & . & $0.0060^{* *}$ \\
\hline & . & . & . & $(2.20)$ \\
\hline $\bar{N}$ & 30975 & 30975 & 30975 & 30975 \\
\hline $\mathrm{F}$ & 512.8 & 517.8 & 347.2 & 1093.5 \\
\hline Adj R-Sq & 0.0320 & 0.0323 & 0.0324 & 0.2974 \\
\hline
\end{tabular}




\section{Table IX \\ Price Impact and Funding Liquidity}

This table reports the regression results on two big net CDS buying groups. At trade $t$, we first calculate the trade percentage change (Price Impact), Trade Change ${ }_{t}-$ Trade Change $_{t-1}$ (Unexpected Price Impact), and Trade Change ${ }_{t+1}-$ Trade Change $_{t}$ (Price Reversal). Next we extract two groups from the sample with net CDS buying at trade $t$ greater than 3 (Big Net Buying) and smaller than -3 (Big Net Selling). For each subgroup, we calculate the monthly average of above three variables, and the difference between two sub-groups. $\operatorname{Ln}(\mathrm{CDO})$ is the logarithm of monthly synthetic CDO issuance. VIX is the monthly average CBOE VIX close price. TED Spread is the difference between 3-month LIBOR and 3-month U.S. Treasury rate.

\begin{tabular}{lcccccc}
\multicolumn{7}{c}{ Panel A: Dependent Variable Is Price Impact } \\
\hline Variable & \multicolumn{2}{c}{ Net CDS Buying } & \multicolumn{2}{c}{ Net CDS Selling } & \multicolumn{2}{c}{ Difference } \\
\hline Intercept & $0.744^{* * *}$ & $-0.385^{*}$ & 0.156 & $-0.555^{* * *}$ & $0.732^{* * *}$ & $0.301^{*}$ \\
& $(5.44)$ & $(-1.94)$ & $(1.43)$ & $(-4.72)$ & $(6.17)$ & $(1.68)$ \\
Ln$(\mathrm{CDO})$ & $-0.082^{* * *}$ & 0.021 & $-0.031^{* *}$ & $0.032^{* *}$ & $-0.070^{* * *}$ & $-0.032^{*}$ \\
& $(-4.34)$ & $(1.03)$ & $(-2.09)$ & $(2.53)$ & $(-4.39)$ & $(-1.70)$ \\
VIX &. & $0.012^{* * *}$ &. & $0.008^{* * *}$ &. & 0.005 \\
&. & $(3.60)$ &. & $(4.10)$ &. & $(1.64)$ \\
TED Spread &. & $0.268^{* * *}$ &. & $0.194^{* * *}$ &. & $0.116^{* *}$ \\
&. & $(5.68)$ &. & $(6.45)$ &. & $(2.55)$ \\
\hline $\mathrm{N}$ & 87. & 87. & 79. & 79. & 79. & 79. \\
F & 18.8 & 36.7 & 4.3 & 38.4 & 19.3 & 13.1 \\
Adj R-Sq & 0.1717 & 0.5546 & 0.0412 & 0.5901 & 0.1896 & 0.3184 \\
\hline
\end{tabular}

Panel B: Dependent Variable Is Unexpected Price Impact

\begin{tabular}{lcccccc}
\hline Variable & \multicolumn{2}{c}{ Net CDS Buying } & \multicolumn{2}{c}{ Net CDS Selling } & \multicolumn{2}{c}{ Difference } \\
\hline Intercept & $0.589^{* * *}$ & -0.299 & $-0.553^{* *}$ & 0.104 & $1.247^{* * *}$ & -0.296 \\
& $(4.94)$ & $(-1.66)$ & $(-2.29)$ & $(0.27)$ & $(4.25)$ & $(-0.69)$ \\
Ln(CDO) & $-0.064^{* * *}$ & 0.018 & $0.061^{*}$ & 0.006 & $-0.138^{* * *}$ & -0.005 \\
& $(-3.83)$ & $(0.97)$ & $(1.87)$ & $(0.14)$ & $(-3.49)$ & $(-0.11)$ \\
VIX &. & $0.008^{* * *}$ &. & $-0.016^{* *}$ &. & $0.025^{* * *}$ \\
&. & $(2.84)$ &. & $(-2.33)$ &. & $(3.40)$ \\
TED Spread &. & $0.238^{* * *}$ &. & 0.107 &. & 0.170 \\
&. & $(5.57)$ &. & $(1.08)$ &. & $(1.57)$ \\
\hline $\mathrm{N}$ & 87. & 87. & 79. & 79. & 79. & 79. \\
F & 14.7 & 29.5 & 3.5 & 3.0 & 12.2 & 13.2 \\
Adj R-Sq & 0.1374 & 0.4983 & 0.0311 & 0.0726 & 0.1252 & 0.3198 \\
\hline
\end{tabular}

Panel C: Dependent Variable Is Price Reversal

\begin{tabular}{lcccccc}
\hline Variable & \multicolumn{2}{c}{ Net CDS Buying } & \multicolumn{2}{c}{ Net CDS Selling } & \multicolumn{2}{c}{ Difference } \\
\hline Intercept & $-0.165^{*}$ & -0.175 & $0.773^{* * *}$ & 0.337 & $-0.907^{* * *}$ & -0.294 \\
& $(-1.96)$ & $(-1.08)$ & $(4.22)$ & $(1.06)$ & $(-4.63)$ & $(-0.91)$ \\
Ln(CDO) & 0.010 & 0.010 & $-0.084^{* * *}$ & -0.047 & $0.091^{* * *}$ & 0.038 \\
& $(0.89)$ & $(0.61)$ & $(-3.38)$ & $(-1.42)$ & $(3.42)$ & $(1.14)$ \\
VIX &. & 0.003 &. & 0.005 &. & -0.006 \\
&. & $(1.16)$ &. & $(0.89)$ &. & $(-1.06)$ \\
TED Spread &. & $-0.100^{* *}$ &. & $0.138^{*}$ &. & $-0.227^{* * *}$ \\
&. & $(-2.59)$ &. & $(1.82)$ &. & $(-2.93)$ \\
\hline $\mathrm{N}$ & 87. & 87. & 81. & 81. & 81. & 81. \\
$\mathrm{~F}$ & 0.8 & 2.5 & 11.4 & 6.0 & 11.7 & 9.0 \\
Adj R-Sq & -0.0024 & 0.0501 & 0.1150 & 0.1578 & 0.1180 & 0.2314 \\
\hline
\end{tabular}

